\title{
Transfuguismo y crisis postelectoral en el proceso de reinstitucionalización democrática
}

\section{César Delgado-Guembes}

"La palabra tránsfuga es un adjetivo que están utilizando algunos sectores de la prensa para quienes nos sentimos con la libertad de poder adoptar con valentía una opción que nos parece mucho más eficiente que otra. Por ejemplo, mantenerme en Perú Posible era ser cómplice de una serie de actitudes como la de la "marcha de los cuatro suyos" y era totalmente relegado dialogar. Era totalmente frustrante, porque lo que más hubiera deseado era seguir en el partido. Yo renuncio a Perú Posible porque no quiero ser cómplice de la muerte de un ciudadano y se había abierto una brecha entre los soldados de Perú Posible, representantes en el gobierno y la estructura partidaria; y me retiro como independiente y opto por una invitación del Presidente de la República para Perú 2000. Yo hago política social, sin demagogia».

Alberto Kouri, Revista Gente, Ed. N²1342, 13 setiembre 2000

En los a veces espinosos senderos que comunican la ciudad de la política y el edificio del derecho, las transiciones de la hegemonía autoritaria a la pluralidad de la democracia opacan las normalidades de la dogmática constitucional con ambigüedades impredecibles por la racionalidad formal de la normatividad. La crisis del 14 de setiembre llevó al presidente Fujimori a anunciar, dos días después, el adelanto y aceleración de la agenda de fortalecimiento institucional y democrático, y con ello a romper una vez más la regularidad constitucional prevista en el documento de 1993. 
Era la segunda vez que lo hacía, aunque en esta oportunidad en un sentido inverso. Para apartarse prematuramente, y para ceder su lugar a un nuevo mandatario y gobierno, antes del vencimiento del período de cinco años de fresco estreno. En 1992 había gobernado poco menos de dos años y supo generar las condiciones para la aprobación de la colectividad, luego de crear condiciones de ingobernabilidad, merced seguramente a una estrategia sicosocial eficientemente diseñada y ejecutada que presentó al Congreso opositor como la fuente del desorden y la causa del desgobierno.

En el año 2000, a menos de dos meses de su tercer período constitucional, consciente de la desaprobación popular y con una percepción clara del sentido de la falta de respaldo de la comunidad internacional, optó por abdicar de su pretensión de gobernar por el período completo. La situación había explotado en tal grado que la ingobernabilidad interna escapó de su capacidad de control: descomposición del régimen político, insubordinación manifiesta de las fuerzas armadas, incapacidad del Congreso de superar y corregir la ilegitimidad, rechazo generalizado del autoritarismo en la colectividad nacional, riesgo de golpe de Estado y presión y exigencia internacional de democratización.

La dinámica de desarrollos políticos extraordinarios como los de fines del invierno de setiembre del 2000, requiere se distingan los momentos o etapas en su evolución. Pueden ser parte de un proceso más o menos largo y lento, o pueden ser ellos mismos un evento súbito y repentino. En la caída de los regímenes autoritarios se produce, en primer lugar, el episodio de la fisura. Es un suceso más o menos dramático que deja expuestas las contradicciones de un proceso de hegemonización política en desintegración, deterioro o en descomposición, que puede tener un período de incubación incierto, pero que siempre resulta de una acumulación de antagonismos que llegan a un punto de no sutura intolerable por los principales sujetos de la coyuntura en el país.

En el caso de la crisis del 2000 el momento de la ruptura puede fijarse poco antes de la fecha de las elecciones del 9 de abril, cuando el electorado inventa a su candidato de oposición para enfrentarlo a la candidatura de Fujimori. El símbolo en que se convirtió el fujimorismo como imagen de una época se desdibujó. Se hizo manifiesta su discontinuidad. El sucesivo reprocesamiento de la realidad a través de los símbolos, discursos y mensajes se agotó. La multiplicidad de una realidad más amplia que no llegó a incorporarse en la ideología del mesianismo y de la eficacia llevó el proyecto al estancamiento. 
En segundo lugar, a la ruptura sigue la crisis, que es el período incierto más agudo, a partir del cual se descompone el equilibrio hegemónico del régimen y se recomponen los escenarios, se rediseñan los discursos, y quedan sin efecto las articulaciones previas ya agotadas, quebrantadas y descompuestas. La crisis es el momento de la emergencia de nuevas reglas, sujetos, posiciones y discursos. Las diferencias son reprocesadas y se fijan nuevos ejes de equivalencia. No hay un núcleo hegemónico claro, sino por el contrario luchas por encontrar alianzas y articulaciones que definan una nueva correlación y fuerza hegemónica en un escenario por venir. El momento de la crisis es un momento sumamente inasible e indeterminable (volátil, es la expresión que más frecuentemente se usa). Lo sólido ha desaparecido de la topografía política. Pero en medio de la volatilidad y fugacidad de su duración, la crisis es también el momento en el que se deben fijar algunos acuerdos o tomar algunas decisiones centrales. Entre esos acuerdos, por ejemplo, que forman hitos en el marco de la crisis propiamente dicha, se cuentan la conducción de la transición por el jefe de Estado que aparece como uno de los ejes de la ruptura; la recomposición de la Mesa Directiva del Congreso, y la reestructuración del Consejo de ministros con un gabinete plural

El tránsito al reequilibrio es la siguiente etapa, y comprende el desenvolvimiento de los actores a partir de los acuerdos básicos adoptados. En la transición deben llevarse a efecto los acuerdos y las decisiones en las que concluye la crisis, a la vez que se producen los actos preparativos y constitutivos de los competidores en la fundación de la nueva normalidad y legitimidad. Es el proceso de cura y de regeneración propiamente dicho, cuando el deseo de democracia y de institucionalidad es preparado para su reinauguración. El cuerpo político no está sano pero sí en proceso de restablecimiento.

A sólo pocas semanas de haberse producido la crisis, cuando es impredecible el camino que tomará la transición en el mediano plazo, en este trabajo se enfoca algunos de los elementos presentes en el momento o período de la crisis, que si bien es en el que menor claridad procesal se tiene, en el que el momento tensional es mucho más alto y en el que la indecidibilidad es mucho más intensa, se trata también de un momento emergente, el momento probablemente más rico en diagnósticos, alternativas, imaginarios y proyectos, a la vez que de una etapa en la que tienden a consolidarse convicciones y consensos mínimos 
muy fuertes y determinantes. Adelantamos pues a título preliminar algunos criterios y elementos de juicio para evaluar y criticar los hechos y los aspectos jurídicos que aparecieron en mayor o menor grado vinculados al surgimiento, clímax y sucesiva declinación de la crisis, a la que posteriormente sucedió la transición, el retorno a la normalidad constitucional, la legitimidad política y el reequilibrio democrático.

\section{I . Antecedentes y naturaleza de la crisis}

El 14 de setiembre del 2000 el Perú fue conmocionado por la revelación de un acto de corrupción funcionarial que comprometía al asesor presidencial Vladimiro Montesinos, y a uno de los parlamentarios tránsfugas, el congresista Alberto Kouri Bumachar de Perú Posible, que trocó su lealtad política en favor de Perú 2000 por quince mil dólares y la expectativa de beneficios pecuniarios adicionales destinados a compensarlo por los gastos en que incurrió en su campaña electoral (alrededor de sesenta mil dólares). Un hecho singular de dos personas públicas, grabado en las propias instalaciones del Servicio de Inteligencia Nacional, ocurrido el 5 de mayo del mismo año, cuando ya se conocía que Perú 2000 no había alcanzado mayoría absoluta en el Congreso, se convirtió quizá en el único y singular suceso más importante que precipitó la caída del régimen del presidente Fujimori.

La historia recordará ese 14 de setiembre del 2000 como la fecha en que se marca la caída del régimen de Fujimori. Ciertamente no se trata de una fecha mágica. Los regímenes caen luego de una sucesión de acontecimientos que los debilitan. Fujimori no debió caer sino concluir normalmente su período constitucional en julio del año 2000. La tozudez, autosuficiencia, falta de visión, desconocimiento de la naturaleza humana, la natural inclinación a la corrupción cuando se carece de control interno y externo, además por cierto de la adulonería y de la infatuación de su círculo, todos ellos y algunos factores más, son elementos propiciatorios del debilitamiento. El 14 de setiembre por eso debe verse solamente como un suceso más que se enlaza a una cadena de actos de socavamiento de la legitimidad.

La fisura final y caída del régimen de Fujimori tuvo, sólo en el año 2000, entre otros, sus principales hitos en :

(1) la no obtención de votos suficientes en la primera vuelta el 9 de abril para alcanzar la presidencia, ni mayoría absoluta en el congreso; 
(2) la ilegitimidad de origen que introdujo el desconocimiento y retraimiento de Alejandro Toledo en la segunda vuelta del 28 de mayo, con el argumento de que el régimen se valía de articulaciones fraudulentas y manipulatorias de la conciencia ciudadana y de la voluntad electoral;

(3) el mensaje recibido en la Asamblea de Windsor, en Canadá, a inicios de junio, que originó el compromiso de iniciar un franco proceso de redemocratización nacional, bajo supervisión de la OEA;

(4) el reconocimiento del foro extraparlamentario de la Mesa de Diálogo, a cargo de un embajador designado por la OEA responsable de facilitar la conciliación y entendimiento a la vez que de supervisar el proceso de reinstitucionalización democrática, con presencia de observadores de la OEA y de actores de la sociedad civil no elegidos al congreso;

(5) la marcha de los cuatro suyos protagonizada por Alejandro Toledo los días 26, 27 y 28 de julio, que en base al ejercicio del derecho de insurgencia buscó originalmente impedir la juramentación del Presidente de la República;

(6) el descenso progresivo de la aprobación y descontento de la población con el régimen, principalmente por las medidas económicas dictadas por el Ministerio de Economía que afectaban tanto a empresarios nacionales como a trabajadores en distintos estratos sociales;

(7) el papel simbólico que cumplieron "el muro de la vergüenza" y la ceremonia del «lavado de la bandera», dos actos llevados a cabo en lugares públicos que permitían expresar el repudio por la ilegitimidad de la doble reelección presidencial y el transfuguismo parlamentario que facilitó la fabricación de la mayoría parlamentaria y del gobierno;

(8) la gaffe presidencial del 21 de agosto del 2000, en el caso del tráfico de armas de Jordania a las FARC de Colombia, en el que el afán por el protagonismo del presidente Fujimori, unido a las estrategias del poder negro de Vladimiro Montesinos, llevó al ridículo internacional al gobernante peruano, al detectarse la participación de militares peruanos en ejercicio como receptores de los cuarenta mil fusiles en un contrato que suponía el Perú como destino final;

(9) el levantamiento institucionalista del comandante Ollanta Humala y su hermano Antauro Humala el día 30 de octubre del 2000, 
exigiendo la renuncia del Presidente de la República y de la cúpula militar, bajo el argumento de que el suyo era un gobierno ilegítimo y por lo tanto la jefatura de las fuerzas armadas estaba en manos de un impostor; $y$,

(10)la comunicación del gobierno suizo del 2 de noviembre del 2000 sobre tres cuentas en bancos de la confederación, a nombre del ex asesor presidencial Vladimiro Montesinos, por el monto de cuarentiocho millones de dólares, que provendrían del lavado de dinero (narcotráfico, chantajes, extorsiones, comisiones por venta de armas, etc.).

Se trata de un caso bastante claro de ruptura de la moral política. No hay violación clara de un imperativo constitucional. Por el contrario. El uso técnicamente adecuado del principio de la mayoría acomodó la voluntad apropiatoria del poder a las leyes. Es un caso claro y flagrante, por eso, de inmoralidad política no censurado expresamente por la Ley fundamental. Es un hecho políticamente incorrecto en la concepción dominante repudiar mediante la lógica y elementos de la transacción dineraria para adoptar una posición política favorable frente al gobierno. No se admite sino que se rechaza la negociación del favorecimiento u oposición al gobierno por un monto de dinero. La posición política, de este modo, es percibida como una cuestión de principios mínimos que no deben ni pueden ser objeto de compra. La comunidad está de acuerdo en que no es virtuoso apoyar o cuestionar al gobierno "por un plato de lentejas", más allá de que el plato venga presentado en vajilla de plata, barro o porcelana, o si consiste en cien mil o en quince mil dólares, o en el alquiler de un camión para realizar «obras de bien social».

Son dos aspectos en un mismo hecho trascendental en la historia política y constitucional del Perú. El primero, la oferta y venta de la adhesión de un representante a fin de asegurarle mayoría a un grupo político, como un acto que causa repudio moral en la conciencia pública. El segundo, la denuncia de Fernando Olivera, Luis Iberico y Susana Higushi y la exigencia de investigación y sanción para los responsables. Son ambos aspectos de naturaleza pública, referidos a la conciencia ética necesaria para el desempeño de cargos públicos.

La revelación del quiste moral al interior del régimen de Fujimori habría de mostrar, a pocos días de la denuncia de los parlamentarios del 
Frente Independiente Moralizador - FIM, que el Perú estaba sujeto a una legitimidad dual. La fuga de Montesinos, favorecida y encubierta por el Presidente de la República y el presidente del consejo de ministros puso de manifiesto el entramado de la complicidad en el gobierno y en la generación del quiste moral en el poder. De igual forma, la propia fuga del sábado 23 de setiembre dejó claro que los más altos mandos de las Fuerzas Armadas reconocían a Montesinos como jefe con mando efectivo sobre ellas y como enlace válido con el jefe del poder ejecutivo. El Comando Conjunto de las Fuerzas Armadas protegió de tal manera a Montesinos que la detención que llevó a cabo un general de brigada, un coronel y un capitán quedó sin efecto por orden expresa del general de división Villanueva Ruesta, Jefe del Comando Conjunto.

La dualidad, en efecto, dejó ver de un lado la legitimidad legal en base al voto popular, y la legitimidad efectiva del poder militar que se sustentaba en las armas y en la maquinaria de control y manipulación sicosocial como dependencia del Servicio de Inteligencia. A sólo pocos días de la declaración de la crisis quedó constancia que el Perú contaba con un presidente cautivo del poder militar, a la vez que a un grupo militar poderoso que no podría ejercitar su dominio sin contar con la figura de su representante formal que habilite y articule su poder de modo efectivo ante la comunidad nacional e internacional. Se confirmó que Vladimiro Montesinos era el eje efectivo del poder, con capacidad para influenciar decisivamente tanto en el Presidente de la República como para dominar a los altos mandos militares.

Si bien es cierto que los hechos y situación políticos referidos tienen un carácter eminentemente coyuntural, la magnitud de sus efectos es tal que, primero, permitió conocer la articulación efectiva del poder militar en la estructura constitucional en tal manera que pudo entenderse cómo se constituyó una fuerza hegemónica paralela a la que confiere el régimen electoral, respecto de la cual, además, el sistema representativo y la opinión pública resultan incapaces de controlar y sancionar. $Y$, en segundo lugar, precipitó al gobierno en una crisis insalvable a solamente mes y medio de haberse iniciado, cuando muchos daban por descontado que el presidente Fujimori tenía ya asegurados cinco años más de mandato ininterrumpido.

Esta crisis exigía una salida. Había lesionado no solamente la reputación privada de la persona y de la familia de Alberto Kouri, o la de Vladimiro Montesinos, sino que dejaba al descubierto la ilegitimidad 
del gobierno en el poder ejecutivo y la ilegitimidad de la mayoría parlamentaria y por tanto la condición espuria de la investidura del gabinete Salas; ponía al descubierto, una vez más, mediante el soborno y la corrupción, el recurso a métodos mafiosos y de prácticas hamponescas en el manejo de la política nacional; explicitaba la participación expresa e innegable del Servicio de Inteligencia Nacional; quedaba comprometida por lo tanto la intervención directa de personal de las Fuerzas Armadas como agentes y cómplices de la corrupción política; y, con ello mismo, se proclamó el quebrantamiento definitivo del fujimorato.

\section{Transfuguismo y no imperatividad del mandato}

\subsection{Casuística del transfuguismo}

El transfuguismo es un síntoma importante en la configuración de la ruptura iniciada el 14 de setiembre porque reveló la precariedad política y moral en la que quedó el régimen de Fujimori. Esta precariedad minó de modo explosivo el régimen en dos áreas principalmente. En primer lugar el parlamento; porque quedó claro que la mayoría de Perú 2000 era una mayoría hechiza y, por lo menos en un caso comprada, en otros dos chantajeada y en uno tercero intentada de chantajear ${ }^{1}$, a espaldas de las reglas y de las propuestas con las que se postuló al voto del electorado. $Y$ en segundo lugar al gobierno, porque los votos de investidura que recibió el gabinete Salas contaron con una mayoría igualmente fraguada. La denuncia de la compra de un tránsfuga llevó al país a una severa crisis de gobernabilidad. Una de las mayores crisis políticas en los últimos setenta años.

El transfuguismo es pues un síntoma importante y, además, decisivo, de la ilegitimidad del gobierno de Fujimori. Dejó en el más grande

1 Compra en el caso del congresista Kouri; los dos chantajes serían los de la congresista Ruby Rodríguez y el congresista Juan Mendoza del Solar; y el intento de chantaje el del congresista Jorge Chávez Sibina, ex alcalde de la ciudad de Iquitos (quien recibiera ofertas del general Villanueva Ruesta, Jefe del Comando Conjunto de las fuerzas armadas para que se pase a Perú 2000 a cambio de solucionarle problemas judiciales pendientes). Ver, sobre el último caso, por ejemplo, el diario Liberación, en su edición del sábado 7 de octubre del 2000, p. 8; o La República, de la misma fecha, p. 2. 
descrédito a su principal hombre de confianza y asesor, Vladimiro Montesinos y reveló que estaba capturado y era presa de una fuerza indesprendible del poder, enquistada en su entorno; a la vez que desungió a su gabinete de la virtud de la confianza popular que no pudo nacer del voto de investidura de una mayoría que carecía de capacidad democrática y moral para otorgarla. De igual manera la elección de la mesa directiva del Congreso, y por lo tanto la de la propia presidencia del Congreso y de sus comisiones, estaba, por la misma razón, viciada de nulidad. Presidente de la República, Gabinete, y Presidencia del Congreso, tres piezas clave del poder en el Perú quedaron exentos de virtud política. El misil responsable de tal devastación en el antes monolítico poder del régimen de Fujimori se llamó "compra de tránsfugas».

Es una convicción más o menos aceptada que los regímenes que no cuentan con respaldo en una mayoría parlamentaria propia o compuesta por una alianza a este efecto, simplemente, no duran. Nuestra historia reciente recuerda el mal fin de los períodos 1963-1968, y 19901992, debido a la heterogeneidad o división de mayorías en ambos órganos del Estado. El período 2000-2005 debió poner a prueba dicha convicción. La historia no se cumplió, primero, porque hubo congresistas electos por grupos distintos a Perú 2000 que aceptaron apoyar al presidente Fujimori, y porque se generó un mayúsculo escándalo nacional a raíz de la revelación de la participación del jefe del espionaje y asesor presidencial en la compra de la lealtad del congresista Alberto Kouri Bumachar.

La historia del escándalo del tránsfuga Kouri, por lo tanto, tiene como antecedente inmediato la marea de fugas anterior al inicio del régimen del año 2000, y su corolario es la contramarea de fugas de los congresistas que abandonan Perú 2000. En la marea que va de mayo a julio del 2000 se ubicaron doce congresistas: Alberto Kouri Bumachar, Edilberto Canales Pillaca, Antonio Palomo Orefife y Mario Gonzales Inga, de Perú Posible; Eduardo Farah Hayn, Jorge Polack Merel y Enrique Mendoza del Solar, de Solidaridad Nacional; Luis Cáceres Velásquez, y Roger Cáceres Pérez, del FREPAP; José Luis Elías Ávalos, de Avancemos; Gregorio Ticona Gómez, de Somos Perú; y Rudy Rodríguez Aguilar, del Partido Aprista. Todos ellos pasaron a Perú 2000. En otro grupo se ubican siete congresistas, que no se pasan a Perú 2000 , pero dejan las agrupaciones con las que salen elegidos. Son los congresistas César Acuña Peralta y José Luna Gálvez, de Solidaridad 
Nacional; José Villena Vela ${ }^{2}$, Carlos Burgos Montenegro, Italo Marsano Chumbez, y Daniel Nuñez Castillo ${ }^{3}$, de Perú Posible; y Waldo Ríos Salcedo, del Frente Independiente Moralizador, que abandonaron sus grupos de origen y asumieron la condición de independientes. Son diecinueve congresistas tránsfugas hasta julio del 2000.

Y en la repentina y turbulenta contramarea del 14 al 27 de setiembre se presentan los casos de Eduardo Farah Hayn, Cecilia Martínez del Solar, Luis Ormeño Malone, Fernán Altuve-Febres Lores, Jorge Polack Merel, Moisés Wolfenson Woloch, Gregorio Ticona Gómez, y Mario Gonzales Inga, que dejan Perú 2000. De estos ocho congresistas, hay cuatro a los que se designó como retránsfugas, porque abandonaron Perú 2000 luego de haber llegado a dicha agrupación como tránsfugas de otra. Son los congresistas Farah Hayn, y Polack Merel (ex Solidaridad Nacional), Ticona Gómez (ex Somos Perú), y Gonzales Inga (ex Perú Posible) $)^{4}$.

Dos casos posteriores, ajenos al escándalo del 14 de setiembre aunque consecuencia de los que lo sucedieron, fueron la renuncia de los congresistas Francisco Tudela y Carlos Blanco Oropeza. Francisco Tudela re-

2 En entrevista que le hiciera la revista Gente al congresista Villena Vela, así como a César Dulanto Gaviño y Rosa Guzmán Ganoza, militantes que fueron expulsados por Luis Solari, refirieron que ellos habían renunciado junto con otros miembros de Perí Posible por el sesgo que toma Alejandro Toledo, después de la primera vuelta, rodeándose de personas a las que denominan «los golondrinos», que son el periodista Gustavo Gorriti, Carlos Bruce, y Alvaro Vargas Llosa, quienes copan el espacio de decisiones estratégicas partidarias; desplazando a los militantes y fundadores del grupo; y por la alianza que realiza con partidos políticos y líderes de la oposición con ideas contrarias a las originales, que tenían como mensaje central que Perú Posible no era ni antigobierno ni antioposición. Edición $\mathrm{N}^{\circ} 1342$, del 13 de setiembre del 2000, pp. 24-26

3 De acuerdo a la referencia que hace el congresista Villena Vela, el congresista Daniel Núnez envía una carta a Alejandro Toledo el día 16 de julio, alertándolo sobre la insatisfacción de las bases de Perí Posible por el papel que asumían «los golondrinos" y sobre los efectos de la "marcha de los cuatro suyos". Loc. cit.

4 Sobre los retránsfugas es sobre los que peor concepto guarda la opinión pública. El psicólogo Leopoldo Chiappo afirmaba que «es difícil creer que un hombre adulto pueda tener tales vacilaciones. Yo no confiaría en un tránsfuga que regresa. Ellos pueden renunciar por vergüenza o por disimulo. Si es por vergüenza, es porque los están emparentando con los vendidos. Pero si es por disimulo, entonces es porque así se quedarán con el dinero y con la honorabilidad disfrazada. Son tránsfugas y de nuevo tránsfugas. Son super tránsfugas». Ver la edición del 24 de setiembre del diario Liberación, p. 10 
nuncia a la primera vicepresidencia de la República y a Perú 2000 con ocasión del retorno de Vladimiro Montesinos al territorio nacional el día 23 de octubre, así como por las declaraciones que emite Alberto Bustamante Belaunde, Ministro de Justicia, en el sentido de condicionar las reformas constitucionales sobre recorte del período de mandato presidencial y parlamentario a la aprobación de leyes de amnistía para personal militar y policial responsable de acciones vinculadas al control de la subversión terrorista y el narcotráfico ${ }^{5}$. Y el congresista Blanco Oropeza renunció a Perú 2000, a la vez que a la presidencia de la Comisión de Presupuesto, el día 3 de noviembre, como consecuencia de la revelación de la existencia de las tres cuentas bancarias de Vladimiro Montesinos en el sistema bancario suizo ${ }^{6}$. Lo relevante de ambas renuncias es el papel de liderazgo y representativo que uno y otro congresistas tenían en Perú 2000. No se trata de congresistas sobre los que caiga sospecha alguna de falta ética en su comportamiento parlamentario o político. Todo lo contrario. Puede por eso verse en sus renuncias actos de reivindicación de principios en cuyo nombre se apartan de su grupo. Lo hacen en

5 En su carta al Presidente de la República, Francisco Tudela decía que «resulta imposible para mí compartir un condicionamiento que, aun presentado como una secuencia o "plan de trabajo", genera condiciones adversas de negociación para la necesaria reconciliación nacional, además de introducir más incertidumbres en una crisis que ya afecta muy seriamente la estabilidad política y económica del Perú [..]. Es también imposible para mí admitir las pretensiones políticas contenidas en el comunicado emitido el día de ayer por los ministerios de Defensa e Interior, sin la firma de sus ministros. No puedo dejar de ver una trágica vinculación entre ambos eventos, así como una relación con la llegada, esta madrugada, del doctor Vladimiro Montesinos, quien ofendió a la conciencia moral del Perú provocando el acortamiento del mandato presidencial».

6 En la carta que Carlos Blanco le dirige a la Presidenta del Congreso el 3 de noviembre dice, en referencia al descubrimiento de las cuentas de Vladimiro Montesinos en la banca suiza, que "aún cuando creo que todavía no se ha alcanzado la consecución de esos objetivos [los de las políticas de crecimiento y desarrollo económico del Perú] no puedo dejar de sentirme profundamente consternado, por llamarlo de alguna manera, ante las serias y graves denuncias que se han formulado en contra de quien ha estado ligado cercanamente al manejo político del gobierno y del país [se refiere a Vladimiro Montesinos]. Al tomar conocimiento en las últimas horas de esos graves hechos, que ya no son de naturaleza aislada, si no que -al parecer-forman parte de una acción permanente y constante, que linda ya con lo delincuencial, me resulta insostenible seguir manteniendo sólo una actitud de cuestionamiento y discrepancia al interior de nuestra agrupación». 
nombre de sus conciencias. El hecho objetivo del apartamiento de Perú 2000 estuvo motivado, según sus propias declaraciones, en su discrepancia frontal con la corrupción que se había instalado en el manejo del país a través del papel protagónico y decisivo en una esfera importante de la vida pública por Vladimiro Montesinos.

Entre los veintitrés congresistas que hacen abandono de las agrupaciones por las que salen elegidos, cabe, de igual manera, distinguir situaciones distintas ${ }^{7}$. Una situación positiva del transfuguismo fue, por ejemplo, la renuncia de la congresista Cecilia Martínez del Solar viuda de Franco a Perú 2000 cuando por desavenencias con su grupo respecto al impropio y contemplativo tratamiento del congresista Alberto Kouri, se autoexcluyó. Otra podría ser igualmente la del caso especial del congresista Juan Carlos Mendoza del Solar ${ }^{8}$, quien anuncia su retiro de las filas de Perú 2000 el 27 de setiembre, luego de calificar como un error haber dejado Solidaridad Nacional, de anunciar el intento de conformación de un grupo parlamentario favorable a Vladimiro Montesinos como consecuencia de una maniobra presuntamente militar y a cargo de personal del Servicio de Inteligencia del Ejército, con el propósito de desestabilizar el gobierno y crear condiciones favorables para un golpe de estado en el plazo de veinte días que haría viable el retorno de Montesinos del extranjero?

7 El ingenio popular encontró el modo de diferenciar algunos subtipos dentro del transfuguismo. La República del 27 de setiembre señalaba, por ejemplo, que «las lecciones que el Congreso les entrega a los peruanos no tienen parangón. A los opositores que se cambiaron de bancada antes de 28 de julio los llamaron "tránsfugas". A los que votaban con el oficialismo sin renunciar a la oposición los designaron como "topos". ¿Cómo calificar a los parlamentarios que supuestamente cambian de bancada política pero siguen siendo los mismos?: travestis». Ibid, columna El Ofidio, p. 4. Otra categoría a la que se recurre para explicar la volatilidad parlamentaria es la de volantuzos, que describiría a quienes desde una opción básica respaldan en unos casos a la mayoría, y en otros a la oposición.

8 De acuerdo al Obispo de Arequipa, Monseñor Fernando Vargas Ruiz de Somocurcio S.J., el congresista Juan Carlos Mendoza es muy noble y fue engañado, presionado, asustado y chantajeado por el señor Montesinos, quien lo llamó para decirle que él era bueno con sus amigos, pero que si no obedecía sus órdenes su padre pagaria las consecuencias. Ver el diario Liberación, del 30 de Setiembre del 2000, p. 2

9 En su denuncia el congresista Juan Carlos Mendoza, hijo del ex diputado arequipeño por Acción Popular en el período 1980-1985, Enrique Mendoza Nuñez, afirmó que el viernes 23 de setiembre acudió a su domicilio a las 5 de la mañana una 
En otro grupo se ubican tránsfugas como el congresista José Luis Elías, quien aún cuando no renunció a Perú 2000 luego de las revelaciones del video presentado por Fernando Olivera, dejó percibir su incomodidad por el hecho de haber cambiado de opción política al inicio del período constitucional cuando pedía en los medios de comunicación que no se confunda a todos los parlamentarios en los mismos supuestos de inmoralidad en que se exhibió al congresista Alberto Kouri Bumachar. De esta manera, pretendía explicar que él no había recibido dinero a cambio de su adhesión a Perú 2000, aunque no llegara a explicar cómo es que actuó en forma desleal frente a la agrupación Avancemos, la lista en la que consiguió ser admitido para postular, y contra la cual realizó maniobras dudosas durante el proceso electoral relacionadas con la manipulación del régimen de personeros para la impugnación de votos, presumiéndose que valiéndose de un número indeterminado de los más de 700 personeros que acreditó Avancemos en el Departamento de Ica así como de los que consiguió acreditar al margen de la representatividad legal de su agrupación. Del congresista José Luis Elías se decía que había llegado a la lista de Avancemos junto con el candidato Ricardo Flores Chipoco, como infiltrados del Servicio de Inteligencia Nacional en las listas de agrupaciones distintas a la alianza Perú $2000^{10}$.

persona (que no identificó al momento de hacer su denuncia), quien le mostró una carta redactada, según él preparada por la Comandancia General del Ejército, que él firmó, en la que renunciaba a Perí 2000 y se argüía como razones que el presidente Fujimori había faltado a las bases y no había cumplido con renunciar a la presidencia, a la vez que no tenía ya más el liderazgo para gobernar el país. Al momento de concluir el anuncio de su retiro de Perí 2000, Mendoza del Solar afirmó que la misma persona le había traído el texto pre-redactado le había indicado que la finalidad era crear las condiciones para el desorden en el Congreso y en la sociedad con la finalidad de desestabilizarla y favorecer la atmósfera de golpe que debiera darse en veinte días, lo cual significaría el retorno de Vladimiro Montesinos al país. En esa misma oportunidad Mendoza del Solar reconoció su error original de haber abandonado Solidaridad Nacional y pidió perdón a sus electores por haber burlado su confianza. Se especuló que las firmas de los congresistas de Perú 2000 que antecedicron a la de Mendoza del Solar pudieron ser las de Fernán Altuve-Febres Lores, Moisés Wolfenson Woloch, Jorge Polack Merel, o Luis Ormeño Malone. Todos, sin embargo, negaron tal supuesto.

10 Esta posibilidad no ha sido investigada por ausencia de evidencia que sustente tal afirmación. Sin embargo, se conoce que hubo una denuncia ante la Defensoría del 
De acuerdo a las referencias y especulaciones que circulaban en Lima, se decía que otro grupo de tránsfugas estaba integrado por los congresistas vinculados a Vladimiro Montesinos, al Servicio de Inteligencia y con algún vínculo con el CAEN, y con los cuales tendría vinculación y estaría comprometido, igualmente, el Oficial Mayor del Congreso, José Francisco Cevasco Piedra. Uno de dichos integrantes era el caso del congresista Altuve Febres, quien se valió del argumento entre ridículo y fantasioso de que se apartaba de Perú 2000 porque estaba en desacuerdo con un proyecto de ley de reforma constitucional presentado por el gobierno en el que se dejaba sin efecto la opción de la segunda reelección inmediata del Presidente de la República, o el de los congresistas Moisés Wolfenson Woloch, y Jorge Pollack Merel ${ }^{11}$, que igualmente huérfanos de argu-

Pueblo en la que se ponía en conocimiento de dicho organismo las irregularidades encontradas, por lo menos, en el Colegio 6065 de Villa El Salvador, en las que se encontraría implicado incluso el coordinador de la ONPE, un ciudadano de apellido Huamaní, que no solamente facilitó el reconocimiento irregular de personeros de Elías y de Perú 2000, sin autorización de las personeras legales nacionales Auristela Obando ni Ursula Harm Fernández Dávila, sino que él mismo se encargaba de repartir las credenciales. Cuando al momento de denunciar el atropello del funcionario de la ONPE y las irregularidades de Elías Avalos se hizo presente la fiscalía de la nación, se confirmó que la fiscal encargada era la doctora Trabucco, que se había hecho cargo de liberar de responsabilidad a los implicados en el escándalo de las firmas falsificadas. El caso no prosperó.

11 Del congresista Polack afirmó la congresista Miriam Schenone en el programa vespertino 24 Horas del jueves 28 de setiembre, en el Canal 5 de televisión, estar especialmente decepcionada por la deslealtad e insanía con la que anunció su apartamiento de Perú 2000 valiéndose para ello del insulto al Presidente de la República. La apreciación de la congresista Schenone se justificó en el pedido de Polack de que el presidente Fujimori renuncie a la presidencia, aunque sin expresar condena contra Kouri ni contra Montesinos. Dicha reacción fue interpretada como una provocación a una salida militar en apoyo de Montesinos y determinó que Perí 2000 lo separe de la agrupación. Sin embargo, Polack hizo caso omiso a la sanción y presentó su renuncia. Debe decirse, sin embargo, que la reacción del congresista Polack fue matizada con el argumento de su incomodidad con la digitación de los votos de los congresistas en las sesiones del Pleno. Dijo Polack que se sentía incómodo en Perú 2000 entre otras cosas por el modo cómo la congresista Luz Salgado pretendía maniobrar el voto de los representantes. Ver, por ejemplo, La República, del 27 de setiembre del 2000, p. 8. La posterior denuncia que presenta a los medios de comunicación Polack, cuando por orden directa del presidente de la república se detiene a tres miembros de las fuerzas armadas cercanos a Vladimiro Montesinos, es un elemento adicional que induce 
mentos optan por abandonar Perú 2000 luego de la crisis. Se presumía que el apartamiento de Altuve, Wolfenson y Polack obedeció a la necesidad de contar con mayor libertad para apoyar la continuidad del gobierno sin la presencia de Fujimori, pero manteniendo la dirección del jefe de espionaje nacional.

Distintos son los casos, por otro lado, de los denominados congresistas retránsfugas como Eduardo Farah Hayn, elegido bajo el número 1 en la lista de Solidaridad Nacional y postulaba como Vicepresidente de la República junto a Castañeda Lossio, quien impulsado por las presiones recibidas luego de pasarse a Perú 2000 decide el 25 de setiembre separarse de esta agrupación. O el del también congresista retránsfuga Gregorio Ticona, elegido por Somos Perú, quien luego de la invitación del Presidente de la República renuncia a dicha agrupación para pasar a Perú 2000 y luego de la crisis del 14 de setiembre renunciar a Perú 2000, dijo él, por indignación con la situación generada, destacando de esta manera lo que parecería ser su limpieza y salud ética respecto al pacto mercenario sujeto a uno o varios pagos a cambio de la defensa de Perú 2000 en el Congreso $^{12}$.

Para formarse el criterio sobre los aspectos involucrados en el transfuguismo, revisamos en seguida algunos de los aspectos más saltantes de su estructura desde el punto de vista jurídico.

\subsection{Elementos objetivos}

Los elementos objetivos del transfuguismo son el abandono del grupo con el que es elegido el representante, y el alineamiento sucesivo con otro grupo. Sin embargo, estos dos actos no tienen porqué ser en sí mismos negativos. Puede ser perfectamente correcto, lícito y hasta

a asumir que él sería efectivamente uno de los congresistas que respaldaba de manera efectiva al ex asesor presidencial desde el congreso.

12 Ticona fue el congresista a quien correspondió reemplazar a Gustavo Mohme Llona a su fallecimiento, luego que se urdiera los cambios en la lista de su grupo parlamentario para evitar la elección de Heriberto Benitez Rivas. Poco antes de la instalación del congreso denunció que recibió presiones para su incorporación a Perú 2000. De él se decía que se le tenía pendiente la iniciación de juicios de malversación, peculado y narcotráfico, elementos que pudieron servir como factores de chantaje para su pase a Perú 2000 . Ver al respecto, por ejemplo, las referencias aparecidas en Liberación, en su edición del 24 de setiembre, p. 11. 
encomiable que, en algunos casos, un representante se desafilie del grupo con el que llega al Congreso y se incorpore a otro.

Uno de los argumentos legales utilizados para fundamentar el cambio de una agrupación a otra es la libertad de asociación que consagra la Constitución en el inciso 13 del artículo $2^{\text {o13 }}$. Al amparo de esta norma se consagra el derecho de toda persona a asociarse. La libertad de asociación es, en efecto, un derecho que debe ser respetado plenamente en la esfera privada. A nadie puede obligarse a pertenecer ni adscribirse a una entidad contra su voluntad ni, por lo mismo, a permanecer en la que no desee.

La duda se presenta en términos de si los representantes que postulan con la posición y programa de una agrupación o movimiento político ante la colectividad, en virtud de lo cual resultan favorecidos con la preferencia del electorado, tienen plena libertad de mudar la adscripción política con la cual solicitaron el voto de la ciudadanía. Más aún en casos tan singulares y particulares como el de las elecciones del 9 de abril del 2000, en el que la población tenía la idea y conciencia clara de la polarización franca y extrema entre la mayoría hechiza y los distintos grupos de oposición.

Un aspecto importante en la evaluación del transfuguismo consiste en los distintos momentos y estructura institucional en los que ocurren los cambios de adhesión. Hasta julio del año 2000 los principales y más notables casos de tránsfugas, que ciertamente fueron comparativamente escasos, se llevaban a cabo como resultado del desarrollo de la historia política. Generalmente se debía a discrepancias surgidas como consecuencia de declaraciones o acciones adoptadas por la mayoría o las minorías a las que cada tránsfuga pertenecía. Podría tratarse de la

13 Este fue el argumento que expuso el congresista Eduardo Farah cuando fue entrevistado en la edición especial del programa 24 Horas del día miércoles 27 de setiembre, al ser entrevistado por Eduardo Guzmán. Lo más extraño e incomprensible del congresista Farah consistió en que él postuló por Solidaridad Nacional con el número 1 para el Congreso, y además postuló como candidato a la vicepresidencia de la República. Parece poco serio que un líder de la importancia que tenía Farah en su organización optara por pasar a Perú 2000 sin que mediara ningún suceso excepcional que ameritara su apartamiento de Solidaridad Nacional. Su explicación era que él discrepaba de la posición de quienes creían que el rol del congreso es investigar, porque para él lo que debía hacer era legislar, pero que para legislar necesitaba ser parte de la mayoría. 
desavenencia con la dirigencia del propio grupo. Pero igualmente podría tratarse del desarrollo de la simpatía con un grupo distinto, por encontrar mayor afinidad como consecuencia del desarrollo propio de la dinámica política dentro o fuera del parlamento.

Lo singular por antonomasia en el transfuguismo del 2000 es que la gran mayoría cambia de grupo aún antes de haberse instalado el Congreso. Es decir, tiene que tratarse de un acontecimiento surgido entre la fecha de la elección al congreso ( 9 de abril) y las Juntas Preparatorias. Es decir, o hubo una razón privada en todos los casos, ajena al desarrollo de la actividad política de unos grupos aún no constituidos en el Congreso; o, contrariamente, hubo algún acontecimiento político serio durante la etapa propiamente electoral que aparta a algunos miembros del grupo por desavenencias insalvables.

No resulta normal esperar que alguien cambie de grupo parlamentario antes de entrar en funciones. Parece inexplicable que antes de haber entrado en acción los bloques o fracciones parlamentarios en el Congreso ya se hubieran producido motivos para apartarse del grupo con el que postulan y llegan al Congreso. Un caso posible podría ser el de algún representante en Perú Posible que por discrepancias serias con la dirigencia de Toledo y de Solari optan por segregarse, en razón del desplazamiento que se constata en este grupo con el cambio de timón que significa incorporar a Gustavo Gorriti, Carlos Bruce y Alvaro Vargas Llosa como figuras decisivas en el posicionamiento radical de Perú Posible frente a la segunda vuelta. Pero esta es una situación especial que afecta solamente a quienes tuvieron un cargo directivo en Perú Posible que fueron desplazados con la injerencia y mayor influencia que llegan a tener los llamados «golondrinos». Este supuesto no alcanza a todos los candidatos de Perú Posible que migran a Perú 2000.

$\mathrm{Y}$ en cuanto a la estructura institucional, es más fácil concebir los cambios de adhesión cuando las agrupaciones políticas carecen de organización sólida, que cuando éstas tienen un aparato, ideología, líderes, programas y posiciones definidas. Cuando la norma cultural respecto a la identidad de los partidos políticos se desvanece resulta más comprensible que quienes participan en la inquietud política sean más condescendientes con su propia adhesión a la agrupación en la que se afiliaron originalmente. Y por la misma razón es más comprensible que la debilidad de la estructura institucional constituya un incentivo para promover, sugerir o proponer el cambio. A una propuesta no censura- 
ble en un contexto de descrédito de los partidos políticos es más fácil que siga una aceptación socialmente menos punible.

Este aspecto está presente en el Perú de fines del siglo XX. Los partidos políticos han sido desacreditados como opción de acción política. Y el descrédito surge tanto por la desvinculación entre las dirigencias y las bases, como por las prácticas clientelísticas que se establece entre bases y dirigencias. Cuando surge la cultura de la retribución por la lealtad al partido, que lleva a entender el acceso al poder y a la estructura y recursos del Estado como una gratificación y fuente de beneficios por la lucha, surge también la corrupción de la actividad política. Una cultura y concepción de tal clase es un marco negativo para la vida política. Facilita e incentiva la participación para tener opciones de empleo, poder, fama o facilidades de viaje.

No es parte de la naturaleza, ni razón de ser de los partidos políticos, que ellos sean concebidos como un aparato ni maquinaria destinada a apropiarse de bienes públicos. Bien entendidos, los partidos políticos deben ser asociaciones para conseguir el bien de la comunidad. En un esquema de partidos competitivos no se entiende que ellos recurran a prácticas inmorales para conseguir el favor del electorado. Su razón de ser no es que el partido gane una elección, sino que prevalezca sobre todo el bien de la comunidad al que cada partido debe aportar. Lo negativo de los partidos políticos es su concepción excluyente, sectaria, que lleva equivocadamente a sus líderes a atomizar la comunidad a partir de la magnificación de una propuesta grupal que tiene carácter privado. El aporte de los partidos es la razón y visión que pueden agregar en la comprensión de problemas comunitarios. No en la demostración ni ostentación de la fuerza de sus propias razones o propuestas, sino el reconocimiento de su condición fragmentaria en el marco de opciones plurales de la sociedad.

La ventaja principal de contar con partidos políticos es la facilidad de difundir la preocupación por la comunidad en la propia comunidad. Esto quiere decir que los partidos políticos deben concebirse como agencias de interés público y comunitario. Tal empresa, si se realiza en términos del interés público que se obtiene a partir de la admisión de la condición fragmentaria y plural de la propia propuesta, es una ventaja pública y comunitaria. No lo será si se retiene el interés apropiatorio y excluyente a partir del cual se quiere hegemonizar de manera totalitaria, absoluta, las posiciones del partido como si contuvieran, sólo ellas, la sintesis de toda la pluralidad comunitaria. 
Por ello, en un contexto en el que la ausencia de concepción plural de los partidos ha generado la censura social a las prácticas apropiatorias y clientelísticas de las asociaciones políticas, es fácil entender que el desdibujamiento y volatilidad de las nuevas organizaciones, carentes de ideología y programas rígidos, carentes también de cuadros permanentes, y carentes hasta de líderes que representen algún grado estable de permanencia, congregue a individuos que no reconocerán lealtades rígidas a las agrupaciones a las que pertenecen. Si los partidos de antaño se transforman en los clubes del siglo XVIII y XIX, el sentimiento de pertenencia, de adhesión y de pertenencia se pierde. El tipo de sujeto político que se vincula a una asociación política percibe que su agrupación no es un cuerpo cerrado sino abierto, fragmentario y plural de valores, donde los suyos también exigen un espacio. El individualismo se apodera de un nuevo tipo de concepción del partido, y la ideología prevalente es la del interés personal, y la visión personal de la comunidad y de los bienes públicos.

Un contexto similar es el que puede percibirse en la sociedad política en la que acontece el transfuguismo de mayo a setiembre en el Perú del siglo XXI. La severidad con la que pudo censurarse y hasta castigarse a quienes mudaban de opción política ha sido convertida en una tolerante aunque doliente mirada de lo que ocurre. Tolerante porque es posible comprender que los partidos han sido concebidos como un mal y que es mejor que adopten las estructuras laxas actuales, y por lo tanto que acojan en ellos a individuos que no tienen afiliación a un credo sino a una voluntad más o menos gaseosa e indeterminada de hacer política y de servir. Y doliente porque en el fondo no deja tampoco de reconocerse que la situación de indeterminación de los proyectos partidarios no es tampoco la deseable, porque de este modo se pierde la capacidad cohesionadora de los equipos que tienen a su cargo el ordenamiento de la vida política.

Tolerante, entonces, porque es necesario que prevalezcan los espacios de libertad en los que los individuos pueden optar por puntos de vista que no tienen porqué ser los de la mayoría de su agrupación. Y doliente porque se esperaría que fuera posible que la vida política estuviera menos fragmentada y desordenada. Es la concepción de la vida política como un espacio desintegrado en el que la identidad de lo común escasea. Lo político es vivido como una paradoja irresoluble. Por eso se carece de severidad para sancionar al tránsfuga. 
El tránsfuga, en este marco institucional y conceptual, es él mismo una expresión de la volatilidad y carácter fragmentario y patológico de la experiencia de la esfera pública, a la que se ha trasladado la propia volatilidad y carácter fragmentario y patológico de la experiencia íntima y privada. La cultura e instituciones favorecen el desborde partidario porque la lealtad al partido no es tampoco un bien público. El partido es un espacio de intermediación y no de acoplamiento ni cimentación de la voluntad comunitaria. La voluntad comunitaria no es concebida como ajena a los individuos, a los que asiste todo el derecho y libertad de escoger con quién se asocian.

Un aliciente más, como si lo anterior ya no bastara, es que la propia estructura legal incentiva la mayor dispersión y atomización cuando aplica la fórmula del voto preferencial como medio para paliar la voluntad de las dirigencias de la asociación política. El voto preferencial consagra la individualización de la representación y desautoriza a los partidos. Su sentido y razón de ser surgió de la época en la que se concebía a las dirigencias como un super poder que manipulaba la dirección del partido. El voto preferencial modulaba dicho poder. Servía para enfatizar la capacidad del elector de discriminar entre los candidatos con independencia al criterio de la dirigencia del partido.

Por eso el uso del voto preferencial en una estructura de partidos fuerte tiene una utilidad que se convierte en práctica potencialmente perniciosa si la estructura no es sólida, o más bien inexistente. Su uso tiende a elevar al representante encima del grupo que lo postula a límites fuera de todo control, y favorece un clima de antagonismo o conflicto al interior del grupo, ya sea entre los candidatos y la dirigencia del grupo, o de los candidatos entre sí; y ello además del grado de incertidumbre que siembra en el electorado que, en un esquema de distrito único, no tiene criterios ni elementos de juicio suficientes para escoger al candidato con el que mejor identifique sus opciones.

¿Cómo no exigir en semejante contexto normativo que se reconozca el derecho de cada quien de agruparse y de votar por el representante que le parezca?. Los tránsfugas tienen respaldo en la estructura electoral para definir su adhesión con mayor libertad que si llegaran al congreso bajo un esquema en el que el electorado opta exclusivamente por una lista. El voto preferencial consagra la condición de cada repre- 
sentante como agente del todo social; de la nación entera. La capacidad de intermediación del partido es debilitada a niveles tales que les deja un manejo nulo de exigencia de responsabilidad o de sanciones por su afiliación. El agente del mandato electoral no es el partido, sino el individuo preferido. La subjetividad del representante, por ello mismo, se sujeta a menores límites y es más ancha su capacidad de consumo del espacio público toda vez que llega a través de una elección altamente personalizada.

Quizá como un elemento adicional pueda contarse las causas derivadas de la dirigencia de la agrupación a la que pertenecen los candidatos o representantes. Cabe referir la experiencia en el movimiento Perú Posible, que entre la primera y la segunda vueltas muestra un vuelco en la tendencia y mensaje hacia la población, conforme lo denunciaron algunos de los fundadores del grupo ${ }^{14}$. Si bien Perú Posible, como cualquier otro movimiento, se funda con la expectativa de ganar las elecciones, el grado especial de polarización en el proceso electoral hace que el plan original tome otro rumbo una vez que se define que debe haber una segunda vuelta, y quiénes serán los candidatos que competirán. La circunstancia especial de pasar la primera valla determina a Alejandro Toledo a vincularse y asesorarse por personajes distintos a los que fundan o militan en el grupo, a la vez que a presentar un perfil distinto. La lógica es la siguiente: el país está polarizado y los dos candidatos representan los extremos que concentran las preferencias de la población, por lo tanto, el discurso para presentarse a la segunda vuelta debe reflejar las expectativas de escuchar un mensaje no contemporizador sino radical.

Por lo tanto, Perú Posible se radicaliza y al hacerlo los militantes y adherentes que llegan con un discurso de centro se decepcionan, cuestionan la dirección de la campaña, el mensaje y la aparición de los llamados golondrinos (Gustavo Gorriti, Carlos Bruce y Alvaro Vargas Llosa), asumen una actitud crítica, y progresivamente desaparece la base y motivos que generaron la asociación. La deslealtad o ruptura de confianza no se originó en quienes renuncian (o son expulsados) sino en la percepción de un apartamiento del lineamiento político original.

14 Ver la nota 2 referida a la posición del congresista José Villena Vela, ex Secretario General Nacional Colegiado de Perú Posible, César Dulanto Gaviño y Rosa Guzmán Ganoza. 


\subsection{Elementos subjetivos}

¿Es que en vista de la estructura institucional y normativa en que se da la participación de los representantes, así como en el marco histórico y conceptual en el que participan los actores, no tiene relevancia la motivación y finalidad de representantes y actores en estos casos, a los que debe excusarse por la libertad de asociación y adhesión que la Constitución les garantiza? ¿Pueden agruparse todas estas renuncias a los grupos parlamentarios con el mismo rasero? ¿Puede justificarse todo absolutamente en nombre de las normas, estructuras, instituciones, historia e ideología? Lo principal es que debe estar claro que es la intención defraudatoria, la burla de la confianza, el oportunismo, o la ventaja, la motivación que se condena en el transfuguismo. El elemento subjetivo principal en este tipo de figura no aprobada en la moral política es el componente que advierte la falta de integridad ética. No es materia solamente de cambiar de grupo.

El transfuguismo tiene una connotación peyorativa, censurable. Y lo repudiable es el descrédito con que afecta la vida política a partir de una visión utilitaria o pragmática que desdeña el paradigma de identidad con el que se postuló. Esto es, el transar respecto a valores políticos, a la fe o credo de un grupo, cuya adhesión se abandona a cambio de un bien privado, como puede ser el dinero, ventajas o beneficios particulares distintos totalmente a aquellos que fija la Constitución en retribución por el servicio representativo que se presta a la comunidad con el mandato y cargo parlamentarios. Se censura, igualmente, la anteposición de una preferencia de carácter privado sobre una oferta y postulación públicas ante la comunidad.

El transfuguismo es concebido pues como un tipo de traición, de deslealtad, de infidelidad. El tránsfuga comete un acto contra la buena fe, contra la confianza. Su acto es uno de engaño, de representación y de simulación de una adherencia impropia. Para expresarlo de manera gráfica, el tránsfuga típico presenta rasgos de conductas psicopáticas. Es un mercenario que aboga por una causa opuesta a aquella con la que se identificó públicamente para llegar al Congreso. Es un francotirador que sirve a quien mayor ventaja le ofrece. El congresista Luis Cáceres Velásquez, por ejemplo, decía que adhirió a Perú 2000 porque con dicho grupo iba a poder tener una labor eficaz "en favor del pueblo", que no habría podido alcanzar como miembro de la oposición ${ }^{15}$.

15 Lo cual trae consigo la pregunta sobre la racionalidad a que obedecería optar 
Por eso es que no todos los casos de cambio de grupo parlamentario son asimilables al mismo tipo de transfuguismo. Casos, por ejemplo, como el del congresista Carlos Chipoco que a fines del período 19952000 abandonó Somos Perú para adherirse al Partido Popular Cristia${ }^{16}{ }^{16}$, que conformaba junto con Renovación un grupo parlamentario; o el de los congresistas Alfonso Baella Tuesta y Francisco Cardoso que abandonaron la Alianza Nueva Mayoría-Cambio 90, en el mismo período, para mantenerse como independiente el primero, y afiliarse a Unión por el Perú el segundo.

Uno y otro abandonaron los grupos con los que llegaron al Congreso, son casos próximos históricamente, pero en ellos no se advirtió el

por presentarse como candidato por un grupo que, no siendo mayoritario, no podría cumplir con dicha finalidad. Naturalmente que quien quiera que postula al congreso no puede predecir si su grupo será finalmente el grupo mayoritario, si compondrá una de las minorías, o si, sencillamente, no llegará a tener representación en el congreso. No obstante, no es menos cierto que quien postula también prevé, primero, que cabe que sólo llegue a ser un grupo minoritario desde el cual su papel no será lo eficaz que podría ser el grupo mayoritario; y segundo, que cabe que desde la minoría puede igualmente servirse al pueblo mediante la propuesta de obras como mediante el control del ejercicio del poder por el gobierno y la mayoría. La gestión de la minoría no es solamente la de controlar en nombre de la sociedad a la que representa, sino que tiene igualmente capacidad de propuesta. En cualquiera de los dos casos, sin embargo, lo central es que los congresistas de la minoría son elegidos para representar a quienes creyeron en sus propuestas y en sus personas

16 Lo elocuente del congresista Chipoco es la trayectoria de sus posiciones políticas. Fogoso militante de la izquierda radical universitaria en la década de 1970 durante su etapa estudiantil, especialista en derechos humanos por el Instituto de Defensa Legal en la década de 1980 y en la primera mitad de la década de 1990, postula por Unión por el Perú en 1995, para anclar en un movimiento comparativamente conservador de centro como es el Partido Popular Cristiano. Vista su situación en perspectiva, la pregunta es cuánto de su desarrollo político ha sido resultado del pragmatismo, cuánto ha sido su necesidad de ubicarse oportunamente en los distintos momentos y escenarios que vive el país, y cuánto es consecuencia de una búsqueda honesta de una filiación política que coincida con sus ideales, visión cívica y convicciones sobre el bien político. Durante el período 1995-2000 Chipoco tuvo discrepancias con miembros y líderes de su agrupación parlamentaria por haber asumido posiciones inconsultas no aprobadas por el grupo y, en algún caso incluso asumiendo una representatividad que no le correspondía. Su personalismo y el afán protagónico en su perfil lo enemistaron con los miembros de su bancada; ello lo llevó al aislamiento y sucesivamente a su renuncia y filiación al PPC. 
contorno ni relevancia que se dieron en la experiencia de los sucesos de mayo a setiembre del 2000. Uno y otro caso, además, son distintos. Chipoco, Baella y Cardoso no tuvieron el mismo tipo de razones para desafiliarse de sus grupos. Y los resultados, igualmente, fueron distintos: uno pasa a otro grupo minoritario con menor perfil de oposición, y el otro opta por mantener su independencia sin afiliarse a otro grupo con el argumento de su discrepancia con métodos de toma de decisiones en la alianza Nueva Mayoría-Cambio 90, en una línea argumentativa similar a la que desarrolló la congresista Cecilia Martínez del Solar viuda de Franco en setiembre del 2000.

En el propio período 1995-2000 uno de los casos más notables en los que un representante cesa la afiliación al grupo con el que llega al congreso es el del congresista Carlos Ferrero Costa. Posiblemente un caso como éste es uno en los que menos duda se tendría de que el tránsfuga no es siempre un personaje reprobable en la política. Todo lo contrario. Carlos Ferrero fue permanentemente considerado un paradigma de corrección política. Nadie pudo cuestionar su lealtad a su agrupación. Lo subjetivo, en este caso, no va de la mano con la definición objetiva. Lo reprobable es un elemento inexistente en el hecho objetivo de su renuncia a su agrupación para recuperar su independencia.

Carlos Ferrero mantuvo el equilibrio entre su autonomía y la lealtad a la agrupación hasta que el grupo optó por una posición contraria a aquella que él había anunciado como determinante de una conducta políticamente correcta. Ferrero fue claro en la necesidad de que el proyecto de la alianza Nueva Mayoría-Cambio 90 respetara el núcleo constitucional y que el presidente Fujimori no postule a una segunda reelección. Su buena fe, su fidelidad y su confiabilidad como representante y vocero de la alianza a la que pertenecía eran incuestionables. Cesar su afiliación, tomar distancia frente a ella y renunciar a su grupo parlamentario no dio lugar a crítica, sino por el contrario a congratulación y opiniones laudatorias. Es más. Luego de asumir su independencia no realizó críticas a su ex grupo, sino que prefirió que el hecho pase con la máxima discreción posible. Tomó su independización de la alianza con circunspección y rehuyó de cualquier posibilidad de escándalo que pudiera maximizar el distanciamiento, granjearle alguna suerte de ventaja ante la opinión pública y, por lo tanto, crear el escándalo. Tan positivamente llegó a tomarse su caso que la honradez con la que vio su misión política le valió que Perú Posible lo invitara para que postule 
como candidato a la primera Vicepresidencia de la República en las elecciones del 9 de abril del 2000.

Por eso, el caso de los tránsfugas del año 2000 fue distinto ${ }^{17}$. En muchos de ellos cabe advertir alguna conducta reprochable. Un aspecto común a todos ellos ${ }^{18}$ fue que adhirieron a Perú 2000 antes de iniciarse aún el período constitucional y cuando todavía no se habían incorporado al Congreso ni habían juramentado la Constitución. Las desavenencias internas no tenían cómo haberse producido y, por el contrario, todo parecía indicar que no había motivo razonable para cambiar de grupo. La sospecha crece cuando se recuerda precisamente la urgencia que tenía Perú 2000 de alcanzar mayoría parlamentaria para apoyar las políticas del gobierno del período 2000-2005.

No parece tratarse de una coincidencia que haya habido tantos congresistas electos que hayan accedido a aceptar la «invitación» del presidente Fujimori para incorporarse a Perú 2000. En favor de la suspicacia queda el testimonio pétreo e incontestable de la grabación de la firma del acuerdo y el pago de quince mil dólares por el servicio, a la vez que la recurrencia a la extorsión que se dijo fue otro mecanismo utilizado en casos como el de la congresista Rudy Rodríguez Aguilar ${ }^{19}$, o el del congresista Juan Mendoza del Solar.

Por la evidencia antes referida es importante no caer con facilidad en la generalización de todos los casos en los que se constata una con-

17 Los tránsfugas del período 1995-2000 que pasaron a la alianza Cambio 90Nueva Mayoría, como Javier Noriega, Francisco Pardo Mesones, o Luis Chu Rubio, no fueron denostados por la opinión pública en los niveles de oprobio que les tocó a los congresistas de mayo a setiembre del 2000.

18 Excepciones a tener en consideración son, como ya se ha adelantado, casos como el de José Elías, que dejó Avancemos por discrepancias advertidas durante el proceso electoral, en el que surgieron reproches por su presunta falta de lealtad al grupo, y por anteponer su personalismo sobre la organización, al punto tal que habría aparentemente llegado a entendimiento con la organización de Perú 2000 para contar con personeros que apoyen los sufragios a favor de Fujimori para la presidencia de la república, y de Elías, y María Jesús Espinoza para el congreso.

19 Se afirmó que Rudy Rodríguez Aguilar fue chantajeada para incorporarse a Perú 2000 en razón de que su esposo, el ex diputado aprista en el período 1990-1992, y ex alcalde de la provincia de Piura, José Santistevan Aguilar, tenía algún proceso pendiente ante el Poder Judicial. Un caso parecido al del chantaje contra Juan Mendoza del Solar y su padre, el ex diputado acciopopulista Enrique Mendoza Núñez. 
ducta objetivamente tránsfuga, aunque subjetivamente encomiable y, por lo tanto, no negativa. La realidad es más compleja que los arquetipos que tienden a gobernar las mentes de las personas. No de todos los tránsfugas puede decirse, y a la vez honrar a la verdad al decirlo, que los políticos tienen un super yo acomodaticio, una personalidad camaleónica que se da a falta de una tradición democrática firme, en donde uno no ve que las instituciones trascienden a las personas ${ }^{20}$. Los casos más claros en los que se demuestra todo lo contrario son los de Carlos Ferrero y Cecilia Martínez del Solar. Y ello no solamente porque estamos en una época en la que los individuos no adquieren ni se adscriben a posiciones fijas en la experiencia política, sino porque las razones y motivos de cada persona pueden tener diversas dimensiones.

\subsection{El sujeto pasivo de la defraudación}

¿Y quién es el sujeto pasivo de la defraudación en los casos de transfuguismo? ¿Es el grupo político que lo propuso en su lista de candidatos? ¿Es el electorado que le dio su voto preferencial? En primer lugar, debe quedar claro que las agrupaciones y los partidos son organizaciones que intermedian y viabilizan la expresión de las preferencias y voluntad de los ciudadanos, seleccionando a sus postulantes. El papel organizativo de las agrupaciones y partidos les garantiza un rol trascendental en la configuración de la voluntad política, porque son unas y otros el medio legal reconocido para la postulación. La postulación individual no es factible legalmente. Por esta razón son titulares de un derecho electoral. Agrupaciones y partidos son el único medio que facilita la atribución de la voluntad ciudadana. De ahí que no pueda desconocerse que en algún grado el acto de cambiar de agrupación una vez elegido es un acto que, cuando menos, afecta a las agrupaciones y partidos que postulan a los candidatos.

Pero no obstante la intermediación de los partidos y agrupaciones, el texto constitucional genera un status especial para los representantes, a quienes libera de vínculo con el electorado al establecer que no existe el mandato imperativo. Esto quiere decir que los representantes no están vinculados legalmente con el electorado y que no tienen ninguna

20 La cita corresponde a la afirmación del psicólogo Jorge Bruce, según aparece en la edición del 24 de setiembre del diario Liberación, p. 10. 
obligación frente a ellos. Los representantes no son mandatarios del pueblo, según esta doctrina, sino que responden exclusivamente ante sus propias conciencias. Una doctrina de esta naturaleza no solamente independiza a los representantes frente al electorado y a las promesas o expectativas que declaró ofrecerles, sino que también desnaturaliza y debilita el carácter del vínculo de intermediación que tienen los partidos como agentes de atribución de la voluntad popular.

Por eso, si bien los electores votan por listas y, en algunos casos, por dos candidatos de su preferencia, la técnica electoral debe servir exclusivamente como medio de expresión de la voluntad. La Constitución excluye de manera expresa la naturaleza vinculante de la postulación por una agrupación o partido. En este contexto, ¿cabe imputar defraudación contra el partido o grupo que propone al candidato en una lista, cuando la fórmula contempla la discriminación personalizada del voto a través del voto preferencial? ¿Es constitutiva o declarativa la filiación del candidato a un grupo o partido? ¿No cabría entender que el carácter constitutivo representaría una suerte de mandato imperativo, que condiciona la acción y posición futura de los representantes en los parámetros de la colectividad?

El hecho determinante es el tipo de vínculo que se establece entre el candidato y la agrupación que lo postula. No hay dos casos iguales. En algunas instancias se tratará seguramente de casos de altruismo incuestionable. Pero habrá otros en los que la relación es innegablemente pragmática. No hay manera de predeterminar la intencionalidad a priori. Debe conocerse la relación o las condiciones en las que se produce la afiliación y el reclutamiento. De ahí que mucho de la falta dependa del trato y arreglos al interior de cada asociación política. Cabe que en algunos casos las condiciones hayan sido objeto de un acuerdo de lealtad entre el postulante y la agrupación, pero no hay nada que impida que como consecuencia de una invitación a postular por una lista quede establecido que tal invitación es estrictamente a título personal, sin la expectativa de contar con votos en bloque durante el período parlamentario.

El FIM, por ejemplo, señalaba que había optado por la preparación de acuerdos escritos con sus integrantes sobre este particular. En el extremo opuesto Avancemos ha sido constante al afirmar que el voto de sus integrantes en el Congreso es en todos los casos un voto de conciencia, y que no se recurre al voto por consigna. Dos aproximaciones al mismo problema. En una se espera la vinculación y adhesión 
preestablecida a la organización partidaria. En la otra por el contrario prima la laxitud organizacional, pero se resalta sobremanera el papel de la conciencia individual en la toma de decisiones parlamentarias.

En este contexto, en el caso de Kouri no hubo pacto ni acuerdo previos con Perú Posible en materia de lealtad o vinculación ulterior. $\mathrm{Al}$ parecer se trataba de sobreentendidos. La condición de congresista se rige, además, de acuerdo al estatuto que definen la Constitución y el reglamento del Congreso. Las obligaciones del congresista son las obligaciones que le reconocen estos cuerpos. No lo son las promesas que se hizo ante el electorado, ni las suscritas con las organizaciones por las que llegan a postular o por las que son elegidos. Las obligaciones que resultan de acuerdos con los movimientos, grupos o partidos, en consecuencia, deben entenderse como obligaciones exigibles en el plano de los compromisos privados. No lo son en el plano del derecho parlamentario ni constitucional positivo.

De ahí pues que el supuesto es que la conciencia de cada quien le dicta cómo proceder. Lo que parece resentir la conciencia es el carácter mercantil de la relación adoptada con Perú 2000 para votar con este grupo. Vladimiro Montesinos le realiza un pago para que se verifique una conducta futura y además se realizan tratativas respecto de una subvención futura para compensar gastos electorales (alrededor de sesenta mil dólares). Es un pago adelantado y una negociación sobre hechos y conductas futuras que se pretende que realice y que Alberto Kouri se compromete a realizar. Las condiciones están dadas para que lo haga: una vez electo el cargo de congresista es irrenunciable.

\subsection{Disciplina parlamentaria}

En vista de los casos de desafiliación producidos, ¿existen mecanismos o procedimientos, dentro del derecho parlamentario, para hacerse cargo de esta situación?

Es necesario distinguir dos tipos de situaciones. El transfuguismo de conveniencia y el delictivo. No obstante que a los dirigentes de los grupos los indigne y moleste que sus miembros dejen la agrupación, en el caso de quienes no cometen un ilícito al pasar a otro grupo no hay modo de exigir ningún tipo de disciplina parlamentaria. Lo cual, naturalmente, no excluye las medidas de carácter privado que pudieran preverse dentro del estatuto o reglamento de la asociación que consti- 
tuyen legalmente. Por lo tanto, no es exigible sanción alguna, suspensión, ni remoción del mandato. Es más. Insinuar que pudiera pedirse la revocatoria del mandato supondría una pretensión inconstitucional, en consideración a la disposición del Artículo $134^{\circ}$ de la Constitución, que prevé la disolución como única causal de pérdida del mandato, así como a la disposición relativa a la no imperatividad del mandato que consagra el Artículo $93^{\circ}$.

El segundo tipo, que es en el que se sitúa la hipótesis de Alberto Kouri, comprende los casos de los congresistas que cambian de opción política como consecuencia del cohecho propio o impropio (artículos $393^{\circ}$ y $394^{\circ}$ del Código Penal), y comprenden los casos de chantaje (artículo $201^{\circ}$ del Código Penal) que es el que aparentemente tenía que ver con el caso de los congresistas Rudy Rodríguez y Juan Mendoza del Solar. En el primer supuesto el congresista es sujeto activo del delito; en el segundo es sujeto pasivo. Los casos de transfuguismo por conveniencia no son sancionables penalmente.

En el supuesto de delitos cometidos por un congresista las opciones son dos: o se inicia un procedimiento en la vía ordinaria por delitos comunes, o se inicia una acusación constitucional por delitos de función. El criterio central es la relación entre el delito y la función. Si no tiene relación con el desempeño del congresista ni afecta su actuación la vía a seguir es la ordinaria. Y si es cometido como consecuencia de su status o mandato de congresista, la vía es la de la acusación constitucional.

Lo crucial será la evaluación del cumplimiento del tipo penal así como de las pruebas de su comisión. Si el tipo no se cumple no hay delito y no hay pena. Si se cumple debe haber suspensión o levantamiento del fuero, según que se trate de un caso de inmunidad de proceso (delito común), o de acusación constitucional (delito de función). El procedimiento ordinario deberá tramitarse a instancia de la Corte Suprema, que debe elevar al presidente del congreso el expediente para la evaluación del levantamiento de inmunidad. El procedimiento de acusación constitucional puede iniciarse directamente en el congreso por un representante o por un particular agraviado.

El supuesto de chantaje no es un caso de sanción al congresista, sino a quien lo extorsionó. El congresista sufre y permite el chantaje, pero no es el responsable de su comisión, sino que lo sufre. Es su libertad la que queda menoscabada y disminuida. Ello importa la nulidad de los 
actos que realiza bajo la denominada vis compulsiva, a menos que no denuncie el delito y pudiendo expresar la libre expresión de su voluntad calla el delito.

El derecho parlamentario peruano reconoce en el reglamento del congreso del poder disciplinario del parlamento, adicionalmente, respecto de conductas impropias en relación con el desarrollo de las sesiones, conforme puede verificarse en el Artículo $61^{\circ}$ del Reglamento del Congreso. Sin embargo, es característica de este tipo de ordenamientos la discrecionalidad y flexibilidad de sus fuentes y normas, y por esta razón cabe que el congreso adopte el temperamento de sancionar a uno de sus miembros por actos reñidos con la ética parlamentaria. Esta fue la manera de sentir el caso Kouri cuando en la sesión del 28 de setiembre del 2000 el Pleno acuerda la suspensión de dicho representante por el término de ciento veinte días, que es el máximo que la Constitución permite, sin derecho a haberes.

La sanción se llevó adelante de modo fulminante, sin sustentación ni debate, como una suerte de ratificación del sentimiento de reprobación que su conducta causó. La Moción de Orden del Día fue presentada por Perú 2000 y si bien no hubo unanimidad, el número de votos a favor sí fue significativamente numeroso. Votaron a favor 95 congresistas, se abstuvieron Luis Cáceres Velásquez, Roger Cáceres Pérez, y Anselmo Revilla Jurado. Y no respondieron al llamado de votación cuatro representantes: los congresistas Pedro Vílchez, Absalón Vásquez, Rolando Reátegui y Antero Flores Araoz ${ }^{21}$.

21 En entrevista telefónica que el autor hizo al congresista Flores Araoz el 3 de octubre del 2000, informó que él no votó porque discrepaba del procedimiento utilizado, al haberse aprobado la sanción antes de haberlo escuchado, y que eso contradecía las elementales normas de derechos humanos. Señaló igualmente que no es que no votara porque tuviera alguna razón de índole personal para no perjudicar al congresista Kouri o a su familia, habida cuenta de su proximidad al PPC, porque precisamente las relaciones personales entre ellos no eran las mejores en vista particularmente del tipo de críticas que Alex Kouri realizó contra la dirigencia del PPC, así como por su idea de que partidos políticos como el PPC ya habían dejado de tener vigencia política. Prefirió no votar, a pesar de estar presente porque creyó que de esta manera el suyo era un gesto de protesta, y que no le parecía justificado dejar constancia oficial ni registro de su posición. 


\subsection{El procedimiento de sanción empleado}

La disciplina parlamentaria se entiende referida fundamentalmente a acciones desarrolladas por los congresistas durante el desarrollo de las actividades parlamentarias en las sesiones del Congreso. Esto significa que las sanciones que se aprueban contra los miembros de la institución se refieren a actos ejecutados durante una sesión. La disciplina parlamentaria no es usualmente referida a actos llevados a cabo fuera de la sesión. Conforme a la norma general señalada, es posible advertir que los actos realizados fuera de sede deliberativa no son sancionables mediante el proceso de disciplina parlamentaria.

Sin embargo, como ha sido público y notorio, el congreso optó por aplicarle el máximo de la sanción permitida por la Constitución, aun cuando el hecho no solamente no fue realizado en una sesión de congreso o de comisiones, sino que él mismo todavía no había jurado el cargo, no había sido incorporado, ni el congreso había sido instalado ni iniciado sus funciones. Esto es, el congreso aplicó la tesis de que la disciplina y las sanciones parlamentarias alcanzan a los congresistas más allá de las deliberaciones que se realizan en el pleno o en las comisiones, en primer lugar, y de que los congresistas son pasibles de sanción incluso por hechos o faltas cometidas en su vida privada anterior al inicio de su mandato.

La tesis integrista con la que procedió el Congreso genera varios precedentes. Uno primero es el precedente que se configura con el supuesto de que son actos conocibles y sancionables por el congreso aquellos que ejecutan los parlamentarios antes del inicio en el ejercicio pleno de sus funciones, aún cuando éstos no tengan carácter calificado como judicialmente punible por una corte de derecho. $Y$ un segundo precedente es el que configura el supuesto de que la capacidad sancionadora del congreso puede ser aplicada respecto de hechos no llevados a efecto en una sesión de congreso o de comisiones.

Al parecer, el hecho sancionado es el comportamiento bochornoso, indeseable o falto de escrúpulo con que la conducta de una persona elegida para representar a la colectividad empaña a la institución parlamentaria. La sanción fue impuesta por actos previos al inicio de la función. Pero se entendió, al parecer con claridad meridiana, que no es posible aislar el pago de dinero, del compromiso de pasar a las filas de Perú 2000. El congreso estimó que hay, en consecuencia, una unidad 
indisoluble y que el pago de dinero sin el comportamiento ulterior de actuar como tránsfuga carecería de toda explicación. Montesinos no le obsequió el dinero a Kouri, sino que lo entrega a cambio de su performance como congresista. Hay dos contraprestaciones. Una se ejecuta, por lo menos parcialmente, de inmediato; la otra es una obligación cuya ejecución sólo puede producirse sujeta al cumplimiento de una condición ulterior en la que se consolida el trato: la asunción del cargo y la instalación sucesiva del congreso.

Más allá de los precedentes establecidos, existen algunos aspectos que resultan igualmente importantes en la evaluación del tratamiento que el parlamento le da al caso. Se trata de las garantías que deben presidir los procedimientos parlamentarios. La primera es el derecho de la persona a la que se reprocha su conducta para ser escuchada; la segunda, la condición de que los asuntos sobre los que se decide sean previamente debatidos por el parlamento.

Al examinar estos aspectos no puede dejarse de indicar que la sanción aplicada fue consecuencia de una iniciativa surgida y acordada en la Mesa de Diálogo. Las diversas fracciones políticas estuvieron de acuerdo en sancionar al congresista Kouri en el seno de este espacio paralelo constituido para diseñar la ruta a la normalización política. Consecuencia de ese propósito resultó ser la determinación de sancionar a uno de los principales emblemas de la corrupción y de la ilegitimización del régimen político. Tal decisión fue adoptada sobre la presunción de que lo advertido en la pantalla relevaba de toda otra investigación o evaluación posterior, y de que la constatación visual y auditiva era evidencia suficiente de responsabilidad y culpa moral, por la cual el congreso tenía que adoptar una determinación drástica.

El acuerdo de la Mesa de Diálogo fue en consecuencia la fuente directa del acuerdo de sanción del congreso. Bastó el acuerdo de la Mesa de Diálogo para que se redactara la Moción. Bastó el mismo acuerdo para que se presentara en sesión del pleno dicha Moción. Y bastó dicho acuerdo para que tal Moción sea sometida a votación sin debate alguno, sin escuchar al imputado y sin deliberación especial de los miembros de las diversas fracciones políticas con representación parlamentaria.

El Congreso actuó como notario de acuerdos ajenos sobre los cuales tenía originalmente competencia plena. Menoscabado y emasculado en su función esencial, su desempeño fue el del eunuco, incapaz de 
procreación política. Sin embargo, la castración parlamentaria no es atribuible a la Mesa de Diálogo. Es consecuencia de la condición política que lo trae a la existencia: la ilegitimidad de base lo lisia, y en esta condición la Mesa de Diálogo actúa como la prótesis que compensa la invalidez y parálisis.

Lo anterior no significa que haya razón para condonar el modus procedendi. Simplemente es una ocurrencia traumática que habita en el interior mismo de la institución parlamentaria, y lo más saludable resulta remediar las fisuras de manera que la muerte definitiva del parlamento lisiado se produzca en el marco de una agonía lo menos indigna posible. Parte de esa agonía supuso extraer la excrecencia tumefacta. Es cierto que el cirujano no siguió el procedimiento establecido. Hacerlo habría agravado aún más la condición del organismo y acelerado su perecimiento. Esta especie perversa de transfuguismo, identificable a partir del solo sentido común, demandó la reacción pronta para que la descomposición no infecte al tejido sano.

\subsection{Tipo penal}

Pero, ¿debe enmarcarse el caso de Kouri Bumachar como simplemente un caso indeseable y agravado de transfuguismo? ¿O cabrá imputar voluntad delictiva, y ya no sólo inmoral, al ofrecer su participación en las deliberaciones y votos por una causa justamente opuesta a aquélla por la que postulara al Congreso?. Son dos los temas por aclarar y revisar. El primero es el tipo penal y el segundo si el video es una prueba válida.

En cuanto al tipo penal una primera aproximación ubicaría los hechos y a los protagonistas dentro del conjunto de tipos clasificados como delitos de corrupción de funcionario. En el caso preciso del congresista Kouri su participación en el acuerdo con Montesinos parece adecuarse al tipo de cohecho impropio. Hay aceptación de donativo y ventajas. $\mathrm{Y}$ la finalidad es cumplir actos propios de su cargo. Pero, ¿̨no modifica el caso que Kouri no fuera un congresista aún?

Es pues un elemento del tipo delictivo la condición efectiva de funcionario. Al momento en que Kouri recibe el pago, no desempeñaba el cargo de congresista, dicho pago se realiza con la finalidad supuesta de que el inicio de su desempeño se realice en un grupo político distinto. Esta era la condición para que Perú 2000 pudiera contar con la mayo- 
ría requerida para la elección de la Mesa Directiva. Esto es, el pago es un adelanto con el que se preparar el desempeño ulterior. En otras palabras, se trata o de la preparación de la consumación del delito, o del inicio de un delito preparado cuyo perfeccionamiento y sutura final se prevé precisamente para el momento en el cual se consolide la condición de funcionario público. Son actos previos que concluyen y perfeccionan el delito en un momento posterior.

El pago inicial (así como las tratativas de pagos posteriores sucesivos) se otorga en intercambio y en contraprestación por una situación constante y continua, por un estado permanente posterior cuyo comienzo se proyecta aproximadamente dos meses y medio antes. El pago es para que el inicio del desempeño de las funciones públicas empiece con una calidad específica: la lealtad a un grupo, a una mayoría. Para desempeñar el cargo de congresista a favor de los intereses de Perú 2000. El pago y las ofertas de pago ulterior sirven para que Kouri Bumachar se desempeñe al servicio de las propuestas de la mayoría que él se cumpliría con su adhesión en constituir.

La proclamación de los resultados de las elecciones define su status como congresista y le asegura la permanencia en el congreso en su calidad de representante. La juramentación y la sucesiva instalación y desempeño efectivo de las funciones son una formalidad posterior que consolida la proclamación. Fs cierto que el status de congresista exige la formalidad de la incorporación del congresista y de la instalación del congreso, pero la condición material de representante es anterior a la verificación de tal formalidad. El congresista tiene una investidura material antes de su juramento e incorporación ${ }^{22}$.

22 La materialidad de la investidura parlamentaria es reconocida de modo expreso en la Constitución y en el reglamento del congreso, en relación a la inmunidad de arresto y proceso. Esto quiere decir, que el sistema legal tiene claro y acoge el supuesto de que la incorporación es efectivamente una formalidad indispensable como principio, pero que la irrevocabilidad e irrenunciabilidad del mandato entran en vigor a partir del momento en que queda firme y consentida la proclamación que anuncia la autoridad electoral. El status parlamentario es válido y existe desde la proclamación. No se hace efectivo sino a partir de la incorporación del parlamentario y la posterior instalación del congreso, ciertamente, pero quien quiera que es proclamado y cuya condición no fuera materia de articulación impugnatoria puede considerarse un congresista electo para efectos legales. El desempeño efectivo de la función se inicia con el nuevo congreso, pero el desempeño material del status empieza antes. Por eso es 
Es irrelevante, por eso, a este efecto, si la oportunidad del trato y acuerdo inicial se dio el 5 de mayo, o si se dio el 25 de julio. En cualquier caso, su materialización es con el fin de asegurar la elección de la mesa directiva del Congreso. Kouri y Montesinos conocían plenamente que Kouri ya había quedado electo. La autoridad electoral ya lo había anunciado. El pago se pacta, produce y surte efectos porque Kouri actuaría como congresista de Perú 2000. No habría pago y, por lo tanto, delito, de no ser porque la performance ulterior es verosímil, factible y ejecutable. La performance era el referente del pago. Se paga para que se desempeñe la labor pública de una manera precisa, y a favor de una opción política específica.

Se paga, pues, para asegurar un sentido en la diversidad de actos parlamentarios individuales y corporativos propios de la función parlamentaria. Para integrar y constituir una mayoría parlamentaria; para sustentar las deliberaciones que colectivamente fije este grupo; y para respaldar con el voto las acciones políticas que compete definir al oficialismo en el congreso. Es, castizamente hablando, una compra de posiciones y de votos. Es también la hipoteca de la conciencia y del pensamiento en nombre y cabeza ajena. El dinero es recibido para cumplir un mandato. El acordado y pactado con el agente de la mayoría que paga por el servicio. El congresista Kouri se comprometía, a cambio de una suma de dinero, a favorecer y a apoyar los intereses y causas del gobierno y de la propia mayoría que él debía conformar e integrar.

Si bien es claro que hay pago a cambio de la incorporación en un grupo colectivo opuesto a aquél con cuyo proyecto político se postuló, y la consiguiente adopción de una actitud continua de respaldo a dicho grupo durante el período constitucional, resulta menos claro conocer cuáles son los términos de intercambio en el caso del pago futuro. Esto es, ¿son las tratativas respecto de la expectativa de pagos futuros para abonar deudas por concepto de campaña parte de la figura delictiva? Al parecer dichas tratativas no se hicieron efectivas, aunque quedaron mencionadas dentro de la invitación de Kouri para que Montesinos se pronuncie. A la invitación queda más o menos fijado el trato futuro, aunque no hay certeza del intercambio.

que a partir de la confirmación de su condición de electos reciben la protección del fuero parlamentario: no pueden ser procesados ni arrestados sin que así lo autorice el congreso o la comisión permanente. 
Como ya se ha anunciado, las fiscalías provincial y superior coincidieron en afirmar que Kouri no desempeñaba de modo efectivo funciones como congresista, y en tal virtud se exculpó prematuramente a Montesinos. No obstante el criterio penal de los fiscales, el Congreso tuvo una concepción diferente, pues se valió de su criterio discrecional para aplicar el poder disciplinario que le confiere el Artículo $95^{\circ}$ de la Constitución, y para suspender a Kouri Bumachar por el máximo permisible que equivale a ciento veinte días de legislatura sin goce de haber, en la sesión del 28 de setiembre. Ese fue el resultado de uno de los acuerdos a que se llegó en la Mesa de Diálogo presidida por el Embajador dominicano Eduardo Latorre, respecto del cual mayoría y oposición estuvieron de acuerdo en materializar.

Esa determinación judicial, sin embargo, no agota la tarea fiscalizadora del Congreso, ni precluye la acción jurisdiccional posterior que se derivara de una eventual resolución parlamentaria, a partir de la cual se decida que hay lugar a la formación de causa, a la denuncia penal respectiva, y a la apertura de instrucción subsiguiente. Por lo tanto, el procedimiento de acusación constitucional es la vía parlamentaria adecuada y necesaria para el apropiado examen de la conducta presuntamente delictiva de Kouri Bumachar, como consecuencia del acto de transfuguismo que protagonizó.

\section{8. La Prueba}

Sobre la condición de la prueba, una opción es afirmar que se trata de la comisión de un acto ilícito a partir del cual un funcionario adscrito al Servicio de Inteligencia viola reglas de reserva y secreto profesional, para hacer público un hecho y práctica carente de limpieza ética que dicha institución realiza, supuestamente, en beneficio del Estado. Otra opción es argumentar que la Constitución no ampara el uso del poder en perjuicio del bien común. El bien común, en este caso, es la voluntad electoral. Al apropiarse del video el funcionario del Servicio de Inteligencia permite que se aclare un delito, mediante la difusión de una práctica ilícita y además inmoral destinada a obtener ventajas políticas por medios indirectos y contrarios a los resultados conseguidos mediante el sufragio popular ${ }^{23}$.

23 De acuerdo a las referencias obtenidas por informantes vinculados a las fuerzas armadas, pude informarme que el oficial que obtuvo el video sería el capitán de 
¿Es pues el video una prueba de la falta? La Constitución señala que no son admisibles como pruebas aquellas obtenidas de modo ilícito. ¿Cómo obtuvo el video el congresista Olivera? Una garantía de la ley penal es la seguridad que ofrece a toda la comunidad de que los procedimientos y normas que ella consagra la protegerán en casos de duda o de incertidumbre. Un principio penal es el de la presunción de inocencia. Por ello, quien alegara la comisión de un delito es a quien corresponde probar que éste se produjo. Y para probarlo la propia ley penal establece igualmente cómo puede probarse un delito. Una de esas maneras es que la evidencia haya sido obtenida de manera regular y no de modo ilícito. La evidencia penal no puede obtenerse violando otras garantías que aseguran la integridad y libertad de la persona.

Para argumentar la precariedad de la evidencia contra el congresista Kouri, en la sesión del Pleno del Congreso celebrada el jueves 21 de setiembre, el congresista Luis Delgado Aparicio fundamentó la improcedencia de la evidencia obtenida ilegalmente. La suya se perfilaba como una defensa legal de la legitimidad perdida. Se trataba de cuestionar la calidad de prueba del video presentado por el FIM, a partir del principio de que la evidencia obtenida por medios ilícitos no tiene tal condición. Por ello debe precisarse que son dos las estrategias en la mayoría: la estrategia por la legitimidad, que en realidad es una batalla perdida, y la batalla por la legalidad. La argumentación de Delgado Aparicio es una de carácter legal. Y por ello no tiene utilidad política en una coyuntura en la que la crisis revela la ilegitimidad de un modo inconfundible.

Si debe atenderse al razonamiento legal y a las garantías que éste establece para la persona, bien cabe intentar todos los recursos que el derecho puede proporcionar. De ahí la legítima intención del congresista Delgado Aparicio. Lo que no está en cuestión, de otra parte, es la manera cómo ha quedado reconocido en la convicción general de la población que la falta existió. Tan existió que determinó al Presidente de la República a declinar de su proyecto de continuar en el gobierno. El quid no es la demostración de la ilegitimidad y condición espuria de la mayoría, sino la validez técnica del video como demostración y prueba. La sanción política y social es clara, pero debe determinarse la procedencia de la sanción judicial.

navío Jorge Castañeda, quien se desempeñara como Subsecretario del Comandante General de la Marina algún tiempo antes de laborar en el SIN. 
Más allá de la responsabilidad administrativa o militar que pudiera corresponderle al oficial que violó la confidencialidad del Servicio de Inteligencia al disponer del archivo de videos, la garantía constitucional y penal relativa al carácter reservado e indisponibilidad por terceros de documentos y bienes privados está pensada en términos de la protección del ámbito personal que no es materia de conocimiento público.

La apropiación del video consiste, cierta e incuestionablemente, en un acto de vulneración de la seguridad por la que es responsable el Servicio de Inteligencia, sin embargo, el sistema de seguridad no está libre de responsabilidad. El Servicio de Inteligencia ni sus integrantes se encuentran en un archipiélago de impunidad. Ahora bien, si es cierto que la ilicitud no es un privilegio reconocido y si es cierto que parte de su eficacia depende de que sus actividades no sean objeto del control político ni administrativo normales, ‘acaso no debe ser igualmente extraordinario el único medio como se obtenga información sobre las actividades que la moral y el régimen jurídico vetan para toda la sociedad?

Si es cierto que solamente mediante la vulneración de la seguridad y confidencialidad de quien está dentro del sistema es como puede obtenerse evidencia de la ilicitud, del carácter delictivo o de la inmoralidad del Servicio de Inteligencia, ¿son aplicables de modo general las normas sobre obtención legal de las pruebas respecto del Servicio de Inteligencia? Responder afirmativamente equivaldría a consagrar la impunidad. Y si de lo que se trata es de asegurar la convivencia con un grado mínimo de valores morales, la respuesta debiera ser que la impunidad no puede ser un resultado amparado por el sistema jurídico. El derecho sirve a valores ajenos a él mismo. El derecho no es un sistema cerrado y suturado sino abierto a la comunidad. Por eso cabe adoptar como criterio para decidir este caso, el análisis de la evidencia misma, más allá de que los medios por los que se la obtuvo no hayan sido los más ortodoxos. Una pretensión de tal limpieza exigiría el correlato simétrico: que hubiera sido posible que el Servicio de Inteligencia entregue tal evidencia al solo pedido de autoridades con poder para hacerlo.

La pregunta entonces es, ¿si no es factible esperar que el Servicio de Inteligencia habría entregado ese y los demás videos de su archivo por virtud del sólo pedido de la autoridad competente para hacerlo, porque al hacerlo simplemente se autoincriminaría, entonces, cómo no admitir el medio oblicuo del que se valió el congresista Olivera para 
denunciar el acto condenable que dio a conocer al público? Este hecho lleva a la conclusión que no es aplicable la garantía del debido procedimiento para obtención de evidencia cuando los agentes de un acto delictivo no son susceptibles de formas normales ni constitucionales de control. Porque se exime al Servicio de Inteligencia de los procedimientos regulares de control, por esa misma razón no serán procedimientos regulares aquellos con los que se logrará controlar las actividades censurables, ilícitas o delictivas del Servicio de Inteligencia.

Como se ve, hay dos principios en conflicto y es necesario poner en la balanza uno y otro con la finalidad de llegar a la solución que mayor bien cause a la comunidad. Debe prestarse atención a las garantías que se le reconoce al individuo en protección de su libertad, su honra y reputación, a la vez que a la exigencia de mínimos de moralidad colectiva indispensables para la convivencia y confianza en la comunidad. El régimen jurídico no prevé solamente una sociedad de individuos libres cuyos derechos personales deben quedar firmemente garantizados por la ley. El régimen jurídico tiene su sentido de ser también en los márgenes mínimos de convivencia. La ley no puede amparar la irresponsabilidad moral ante la comunidad en nombre de la libertad. Entre ambos polos debe tejerse la argumentación que pondere los valores involucrados. El Perú no es solamente una suma de entes atomizados y éticamente autónomos. Por eso en nombre de valores mínimos de vida comunitaria es exigible de la autoridad que genere mediante su reflexión y raciocinio la regla jurisdiccional que articule un discurso basado en la responsabilidad ante el cuerpo social y político.

Negar la condición de prueba del video que prácticamente todo el Perú ha visto, en nombre de la formalidad y la supuesta garantía individual para quien comete un delito, es una distorsión y ofensa a la conciencia pública no solamente de la comunidad nacional, sino incluso una vergüenza internacional. Existiendo, por lo demás, la voluntad declarada de desmontar el sistema de inteligencia nacional, no debe ser improbable que la revisión que oportunamente se realice en la videoteca y archivos de este sistema permita generar la convicción del grado de evidencia contenido en el video puesto a conocimiento de la opinión pública. Si la voluntad es arribar a la verdad y no solamente realizar trámites y llenar formularios la consecuencia debe ser auténticamente provechosa. El país se hace no solamente mediante la apreciación de indicadores y cifras de rendimiento económico. El país también es la 
conciencia pública y la satisfacción de deudas morales que deben saber honrar la representación nacional y la autoridad jurisdiccional.

\subsection{Fuente de pago}

Otro aspecto relevante en este caso es la fuente del pago, esto es, ¿de dónde sale el dinero para pagar la compra de la representación de intereses, proyecto y posiciones de la mayoría, así como el que corresponderá a los abonos posteriores ofrecidos? Son dos situaciones diferentes, porque en el primer caso hay un acuerdo firme sobre el pase de un grupo a otro; pero en la segunda pareciera tratarse de desembolsos por contraprestaciones no precisamente anticipadas en el acuerdo original.

En la versión del congresista Kouri, él había recurrido a Montesinos como persona privada en busca de apoyo financiero ${ }^{24}$. Pero, ¿era dinero privado de Montesinos, o se trataba del uso de una partida proveniente de los servicios de inteligencia? ¿Es éste el tipo de gastos en que incurre el SIN respecto de los cuales no se da nunca cuenta ante el Congreso?. Estos son los aspectos que debían quedar aclarados en la investigación que debió llevar adelante el Ministerio Público y la Defensoría del Pueblo. Y la ignorancia que rodea a este caso se origina en la falta de control parlamentario efectivo de los manejos del SIN. Este es un hecho y una práctica lamentables que lesionan la salud y la cultura política del Perú. El SIN no debe quedar exento de responsabilidad por las cuentas que maneja, y debe dar cuenta de los gastos que se realizan en su seno.

Entre las hipótesis adicionales que se barajaron se insinuó que el dinero podría provenir del tráfico de drogas, o de las donaciones de empresarios identificados con el régimen de Fujimori. Estas serían las hipótesis complementarias a la de la procedencia de fondos o partidas

24 La televisión chilena entrevistó al congresista Kouri en edición que fue retransmitida por el noticiero 24 Horas de Canal 5 el viernes 6 de octubre, y además de señalar que él no había recibido solamente 15 mil dólares de Vladimiro Montesinos, sino que a dicho monto había de sumarse otros 22 mil 500 dólares que se destinaron a saldar la deuda que tenía con Oscar Duffour Cattaneo o con José Francisco Crousillat, insistió que él había recurrido a Montesinos como persona privada y que el dinero que recibía en préstamo era de propiedad de Montesinos, de quien era amigo personal. 
del tesoro público, que aparentemente debiera quedar descartada a la luz del dictamen del Fiscal Superior que confirmó el del Fiscal Provincial, quien concluyó que no había lugar a la denuncia contra Vladimiro Montesinos porque él, de acuerdo al informe del representante oficial del Servicio de Inteligencia Nacional, no maneja fondos del Estado ${ }^{25}$.

Con la afirmación del Servicio de Inteligencia sobre la no responsabilidad de Montesinos sobre el manejo de fondos públicos se suprimió la voluntad de investigación de la fiscalía de la nación. Ello equivalía a sostener la tesis de que el dinero recibido por Alberto Kouri provenía de fuente privada. La procedencia privada, sin embargo, no excluye la investigación sobre la finalidad del pago. ¿ ¿Fue efectivamente un préstamo para abonar deudas personales? ¿No había relación entre el pago y su afiliación a Perú 2000? ¿Son dos hechos distintos sin ningún nexo o vínculo? La tesis de Kouri es que una cosa no tiene nada que ver con la otra. Su argumento tiene como base la atipicidad penal de su conducta, así como la ausencia de conexión o vínculo entre el dinero recibido y su posterior renuncia a Perú Posible y pase a Perú 2000. La impresión que se formó el grueso de la opinión pública, no obstante, es que sí se trató de un abono para conseguir que Kouri decida su pase al grupo de Perú 2000.

Algunas semanas después del destape sobre el caso Kouri-Montesinos, el desarrollo político llevó al país al destape todavía más grave sobre el

25 Las fiscalías fueron especialmente diligentes cuando se pronunciaron sobre el archivamiento del caso. Presentada la denuncia, la fiscal Nina Rodríguez Flores interroga a Montesinos el 18 de setiembre y el día 20 se pronuncia por el archivamiento del caso. Elevado en consulta el pronunciamiento de la fiscal provincial, el fiscal superior Arquímedes Pesantes confirma el dictamen disponiendo igualmente el archivamiento de la denuncia. En ambos casos se recurrió a la especie de que, según el servicio de inteligencia nacional, Montesinos no tenía responsabilidad ninguna en el manejo de fondos públicos, lo que determinó a los fiscales a afirmar que quedaba excluido tal elemento del tipo delictivo. Sobre el caso de Kouri los mismos fiscales afirmaron que no se configuraba el extremo de su desempeño efectivo del cargo de congresista, que de acuerdo al reglamento del congreso sólo empieza una vez que se ha juramentado el cargo y el congreso ha sido instalado. Afortunadamente, luego de la renuncia de Blanca Nélida Colán Maguiño al cargo de Fiscal de la Nación a inicios de noviembre del 2000, significó que el 6 de noviembre se suspenda en sus funciones a la fiscal Nina Rodríguez Flores, así como al inicio de un proceso de investigación en su contra por la comisión del presunto delito de prevaricato en este caso. 
propio Montesinos: el de las cuentas que Vladimiro Montesinos en tres bancos suizos. La sospecha de que los más de cuarentiocho millones que se indicaron tendría Montesinos pudieran haber servido para la labor de composición o construcción de la mayoría parlamentaria, paralelamente a otros actos de extorsión o de chantaje, deja abierta la interrogante de que el pago recibido por el congresista Kouri pudiera, efectivamente, tener origen privado y, además, ilícito, si se llegara a probar que tal dinero provino del lavado de dinero por narcotráfico o por otras maniobras fraudulentas y delictivas del asesor presidencial.

Sea como fuese, el hecho es que el jefe del espionaje nacional actuó para el Presidente de la República y para la mayoría oficialista en el Congreso. Pero es innegable, igualmente, que lo hacía para beneficiarse personalmente al quedar rodeado de una estela de autoridades que en el momento preciso lo encubrirían de toda acción de control y fiscalización. El congresista Kouri, por lo tanto, no habría actuado simplemente como un tránsfuga que recibió dinero para apoyar al gobierno y a su mayoría parlamentaria, sino que dentro de los servicios por los que hipotecó su mandato también debiera incluirse el apoyo y la protección que le debe al propio Vladimiro Montesinos. Parte de esta condición queda configurada con las declaraciones con las que pretende exculparse, apelando la inocente recepción de un préstamo para saldar deudas y compromisos derivados de su campaña electoral así como al origen privado del dinero que le proporcionó Vladimiro Montesinos.

\section{Reflexión final}

El transfuguismo no es un fenómeno parlamentario exento de aspectos controvertidos. Encierra casos encomiables y ennoblecedores de comportamiento político, tanto como otros que generan abyección. El caso que ha concitado la atención reciente de toda la comunidad ha tenido a más de dos protagonistas, aunque el suceso concreto del affaire Montesinos-Kouri es el que ciertamente mayor gravedad reviste. Es grave por razones morales, no menos que por razones políticas. Todo parece indicar que es un caso flagrante de corrupción política que llevará a destapes en cadena de muchísimos otros casos de corrupción en los que el principal actor será el ex jefe del espionaje nacional. Uno de 
dichos destapes, efectivamente, se produjo a inicios de noviembre del 2000, cuando se puso en conocimiento de las autoridades nacionales la indagación llevada a efecto por la banca suiza, que llevaría al Estado a iniciar acciones policiales y judiciales en contra de Vladimiro Montesinos por la presunta comisión del delito de lavado de dinero.

En este trabajo se han cubierto algunos de los más saltantes aspectos de este fenómeno paranormal en la vida parlamentaria del Perú, y la revisión de los distintos aspectos que lo configuran permite concluir que el transfuguismo es sancionable, no en función de los hechos objetivos del pase de un grupo político a otro, sino en razón de los móviles que tienen quienes fugan a otra asociación. Ello significa que el reproche ético que el Congreso expresa a un parlamentario por el soborno presunto que recibe por su pase de un grupo a otro es pasible no solamente de sanción disciplinaria por el Congreso, sino que tiene elementos básicos que permiten inducir que existe una conducta delictiva. La corrupción pasiva, que es un delito de función, es materia de un procedimiento parlamentario: el de acusación constitucional. Compete al congreso examinar las circunstancias, determinar las posibles normas aplicables, evaluar la eventual tipicidad de la conducta según los tipos penales presuntamente relevantes, revisar la motivación y nivel de culpabilidad del denunciado, y determinar si hubo o no infracción penal en cuyo mérito deba el poder judicial incoar el procedimiento regular contra el congresista acusado.

Otro concluible es que el transfuguismo parece deber su explosiva manifestación tanto a la ausencia de control que existe respecto del servicio nacional de inteligencia, como a la estructura debilitada de los partidos políticos. Sobre esto último, una lección que parece enseñar el drama de fines de invierno del 2000 es que es momento de llevar el péndulo al otro extremo en busca del centro. Los partidos deben recuperar la responsabilidad que les corresponde como agentes de intermediación de la voluntad política del electorado en el proceso de reinstitucionalización democrática del país. Para ello debe, a corto plazo, reconocérseles la atribución de definir quiénes deben postular a los principales cargos públicos. Lo cual pasa por la modificación de dos aspectos del régimen electoral: el reconocimiento del distrito múltiple y la eliminación del voto preferencial.

La redemocratización aparece en la vida política del país como un clamor en contra de formas autoritarias del manejo de la cosa pública, 
que llevaron no solamente a la desinstitucionalización de los pilares del Estado y de la sociedad política, sino que estuvieron rodeadas de aspectos perversos vinculados a la amenaza, el chantaje, el chuponeo telefónico. Por eso la demanda de eficacia en el proceso de reinstitucionalización pasa por la renovación de la moral pública. Sin instituciones y autoridades decentes no hay confianza. Una cultura de corrupción y de miedo envilece y hace miserables a los hombres. Por el contrario, una cultura de libertad y de dignidad humana, con amplio y radical respeto y tolerancia para la pluralidad y la democracia favorecen la renovación institucional. Elegir a nuestros gobernantes y representantes es tanto una obligación política como un examen de criterio moral para la ciudadanía. La edificación de nuestra sociedad política, por eso, no depende sólo de quienes gobiernan. Tanta o mayor responsabilidad tienen quienes eligen a la autoridad. A la hora de pedir cuentas, por ello mismo, el ciudadano debe reconocer su propia condición como agente o como secuaz del buen gobierno o, por el contrario, de la complacencia con la corrupción.

Magdalena del Mar, 7 de noviembre del 2000 